IZA DP No. 4756

Stability of Time Preferences

Stephan Meier

Charles D. Sprenger

February 2010 


\title{
Stability of Time Preferences
}

\author{
Stephan Meier \\ Columbia University \\ and IZA
}

Charles D. Sprenger
University of California, San Diego

Discussion Paper No. 4756

February 2010

\author{
IZA \\ P.O. Box 7240 \\ 53072 Bonn \\ Germany \\ Phone: +49-228-3894-0 \\ Fax: +49-228-3894-180 \\ E-mail: iza@iza.org
}

\begin{abstract}
Any opinions expressed here are those of the author(s) and not those of IZA. Research published in this series may include views on policy, but the institute itself takes no institutional policy positions.

The Institute for the Study of Labor (IZA) in Bonn is a local and virtual international research center and a place of communication between science, politics and business. IZA is an independent nonprofit organization supported by Deutsche Post Foundation. The center is associated with the University of Bonn and offers a stimulating research environment through its international network, workshops and conferences, data service, project support, research visits and doctoral program. IZA engages in (i) original and internationally competitive research in all fields of labor economics, (ii) development of policy concepts, and (iii) dissemination of research results and concepts to the interested public.
\end{abstract}

IZA Discussion Papers often represent preliminary work and are circulated to encourage discussion. Citation of such a paper should account for its provisional character. A revised version may be available directly from the author. 
IZA Discussion Paper No. 4756

February 2010

\section{ABSTRACT}

\section{Stability of Time Preferences ${ }^{*}$}

Individuals frequently face intertemporal decisions. For the purposes of economic analysis, the preference parameters assumed to govern these decisions are generally considered to be stable economic primitives. However, evidence on the stability of time preferences is notably lacking. In a large field study conducted over two years with about 1,400 individuals, time preferences are elicited using incentivized choice experiments. The aggregate distributions of discount factors and the proportion of present-biased individuals are found to be unchanged over the two years. At the individual level, the one year correlations in measured time preference parameters are found to be high by existing standards, though some individuals change their intertemporal choices potentially indicating unstable preferences. By linking time preference measures to tax return data, we show that identified instability is uncorrelated with socio-demographics and changes to income, future liquidity, employment and family composition.

JEL Classification: C93, D01, D03, D11, D91

Keywords: preference stability, time preferences, experimental economics

Corresponding author:

Stephan Meier

Columbia University

Graduate School of Business

710 Uris Hall

3022 Broadway

New York, NY 10027

USA

E-mail: sm3087@columbia.edu

\footnotetext{
*We are grateful to Nageeb Ali, James Andreoni, Richard Carson, Julie Cullen, Lorenz Goette, Yoram Halevy, Glenn Harrison, Ayana Johnson, Muriel Niederle, Lise Vesterlund, Michelle White, Chris Wignall, seminar and conference participants at Cornell University, University of California, San Diego, University of California, Santa Barbara, the North America ESA Meeting 2009, Universitat Pompeu Fabra Barcelona, Stanford University and University of Pittsburgh for helpful comments and discussions; and to the Federal Reserve Bank of Boston for financial assistance. The views expressed in this paper are, however, those of the authors and not necessarily those of the Federal Reserve System or the Federal Reserve Bank of Boston. Benjamin Levinger provided excellent research assistance. Special thanks to Marques Benton (Department of Public and Community Affairs, Federal Reserve Bank of Boston) for all his help.
} 


\section{Introduction}

“... one does not argue over tastes for the same reason that one does not argue over the Rocky Mountains - both are there, will be there next year, too, and are the same for all men." (Stigler and Becker, 1977, p. 76)

Individuals are frequently faced with intertemporal decisions. From larger decisions such as how much to save for retirement, and how much to borrow on credit cards, to smaller decisions such as whether or not to have dessert, individuals are required to make trade-offs over time. The preference parameters governing these decisions, that is intertemporal preferences, are generally assumed to be static economic primitives. Economic analysis effectively proceeds from this basis: if changes in intertemporal choice behavior are observed (e.g., if consumers borrow more this year than last), then relative prices or budget constraints must have changed, but preferences remained the same.

It is crucial to know whether time preferences are indeed stable. ${ }^{1}$ Though unstable intertemporal preferences can be incorporated into theoretical models of economic decision-making, empirical analysis is hampered by such instability. Unstable intertemporal preferences would imply that preference parameters have to be separately measured and accounted for in each time period. As such, it is difficult to pin down time-varying preferences and responses to changing economic incentives solely from time-varying behavior. In their seminal work on stable preferences, Stigler and Becker (1977) make the key point that attributing changes in behavior to changes in preferences leaves too many degrees of freedom to be economically interesting.

Despite its clear importance for economic research, relatively little is known about the stability of time preferences. ${ }^{2}$ A few psychological and economic studies show correlation between

\footnotetext{
${ }^{1}$ As Horowitz (1992) points out, time preference stability, or "intertemporal stationarity," is a separate concept from dynamic consistency. Stability is neither a necessary nor sufficient condition for dynamic consistency. Dynamic consistency, or the notion that planned and actual behavior should coincide, has been studied in several experiments including Horowitz (1992) and Harrison et al. (2005a).

${ }^{2}$ Readers interested in the temporal stability of other preferences are referred to Andersen et al. (2008b) who analyze stability of experimentally elicited risk preferences for a sample of 97 Danes and find evidence in favor of stable risk preferences. Stability of other-regarding preferences have been investigated, for example, by Benz and Meier (2008); de Oliveira et al. (2009).
} 
experimental measures of patience and future behaviors such as scholastic achievement (Mischel et al., 1989), borrowing (Meier and Sprenger, 2010) and credit default (Meier and Sprenger, 2009). This evidence, however, is indirect in that stability is identified only under the assumption that a common set of preferences drives both experimental responses and later real-world behavior.

Contrary to the findings noted above, other research shows low (or no) correlation between measured time preferences and intertemporal decisions such as diet and exercise behavior (see e.g., Chabris et al., 2008). Such low correlation in cross-situational behaviors has been interpreted by psychologists as evidence of instability in personality traits or preferences (see e.g., Mischel, 1968; Ross and Nisbett, 1991). ${ }^{3}$ Additionally, experimentally measured time preference parameters vary broadly. Frederick et al. (2002) review the literature and find annual discount factors (rates) ranging from one (zero percent) to virtually zero (infinity percent), possibly suggesting instability in time preferences. The authors propose that at least part of the variance in findings is due to differing experimental methodology and differing sample selection. They also note that "no longitudinal studies have been conducted to permit any conclusions about the temporal stability of time preferences" (Frederick et al., 2002, p. 391). To our knowledge, the lack of longitudinal time preference studies persists to the present. ${ }^{4}$

The current study begins to fill this gap. In consecutive years, we elicit the time preferences of around 1,400 adults from the same subject pool using identical incentivized experimental methods. The experimental methodology was designed to elicit individual discount factors and present-biased preferences (see, e.g., Laibson, 1997; O’Donoghue and Rabin, 1999). This represents the largest study of time preferences with actual payments conducted to date, making it an ideal data set for testing time preference stability. The study was conducted at a tax-filing

\footnotetext{
${ }^{3}$ Low correlation between different indicators of time preference does not necessarily mean that time preference are unstable. Decisions such as smoking and borrowing might be governed by a number of factors independent of time preferences.

${ }^{4}$ In a study of dynamic consistency, Harrison et al. (2005a) have time preference data for 97 Danish individuals that could be used to explore this topic. Observation of the presented data is not suggestive of stability in elicited one month discount factors. Interested readers are referred to Figure $1 \mathrm{C}$, data series $A$ and $A^{*}$ of Harrison et al. (2005a).
} 
center and individuals granted us access to their tax filing data. Thus, we obtain objective information on economically relevant changes in income, unemployment and family composition. Changes in economic variables such as income have long been thought to affect time preference (see e.g., Fisher, 1930). ${ }^{5}$ Study participants are low income such that substantial proportional income changes are observed and changes to employment and family composition are likely to have important economic impacts. Additionally, the tax data also allow us to investigate the influence of future changes to liquidity on measured time preferences by analyzing the effects of the magnitude and timing of tax refund receipts.

Our analysis yields three important results. First, the aggregate distributions of both discount factors and present bias are indistinguishable across the two years of the study. Given the wide historical variation in time preference parameter estimates from experimental studies (Frederick et al., 2002), this demonstrates that when rigorously controlling both the experimental methodology and the sample pool, one can obtain stable aggregate estimates over time. Second, in an individual-level panel analysis, we demonstrate that 60 to 70 percent of the variance in measured time preference parameters can be explained with individual fixed effects. Additionally, the individual-level one-year correlations in measured time preferences are strongly significant and high by psychological standards (see e.g., Costa and McCrae, 1994). These panel results are robust to controlling for longitudinal sample attrition, which is identified by exploiting differences in the distance individuals live from the tax-filing center. The third contribution explores the degree of instability in measured preferences. Some subjects show substantial variation in their measured preferences over time. We find that there exist no demographic correlates for the direction of this instability, nor can one predict differences with economically relevant changes in income, unemployment, family composition or future liquidity. We discuss potential interpretations of these results. Though one can obtain a stable distribution and high correlations at the individual level, the correlations are not perfect. The source of any instability is difficult to pin down. As such, it is unknown whether standard experimental

\footnotetext{
${ }^{5}$ Additionally cross-sectional data show dramatic differences in the rate of time preference between wealthy and poor households (see Lawrance, 1991).
} 
measures are simply noisy or if there exist individuals with highly unstable preferences whose instability is orthogonal to socio-demographics.

The remainder of the paper proceeds as follows: Section 2 presents our methodology for experimentally eliciting time preferences and discusses design details. Section 3 presents results related to stable preferences over time at the aggregate and individual level and discusses sources of potential instability. Section 4 discusses potential interpretations of our obtained results and Section 5 concludes.

\section{Empirical Methodology}

\subsection{The Set-Up}

Evidence in this paper comes from a field study conducted in collaboration with the City of Boston, at a Volunteer Income Tax Assistance (VITA) site in Roxbury, Massachusetts. There are currently 22 such VITA sites in Boston, MA, providing free tax preparation assistance to low-to-moderate income (LMI) households in specific neighborhoods in order to help them claim valuable tax credits such as the Earned Income Tax Credit (EITC). The VITA site in Roxbury is Boston's largest and was established in 2001. Individuals who received tax assistance in 2007 and 2008 were administered identical, incentive-compatible choice experiments to elicit time preferences, resulting in 1684 observations (890 in 2007 and 794 in 2008). Of the participants in 2007, 250 again participated in 2008. That is, we obtain two time preference observations for these individuals.

Conducting time preference experiments at a local VITA site allows us to match time preference measures with tax data and demographic survey data. Individuals consented to our accessing their tax filing data and, for participants in the choice experiments, to combining their tax data with their time preference measures. 


\subsection{Measuring Time Preferences}

Individual time preferences are elicited using identical incentivized choice experiments in both years of the study (for similar approaches, see Coller and Williams, 1999; Harrison et al., 2002; McClure et al., 2004; Dohmen et al., 2006; Tanaka et al., 2009; Burks et al., 2009; Benjamin et al., 2009; Ifcher and Zarghamee, 2009). Individuals were given two multiple price lists and asked to make various choices between a smaller reward $(\$ X)$ in period $t$ and a larger reward $(\$ Y>\$ X)$ in period $t+\tau>t$. We keep $(\$ Y)$ constant and vary $(\$ X)$ in two time frames: in Time Frame 1, $t$ is the present $(t=0)$ and $\tau$ is one month $(\tau=1)$; in Time Frame 2, $t$ is six months from the study date $(t=6)$ and $\tau$ is again one month $(\tau=1)$. The order of the two time frames presented to participants was randomized. In both time frames $\$ Y=\$ 50$ and $\$ X$ was varied from $\$ 49$ to $\$ 22$ (see the instructions in Appendix A.2). ${ }^{6}$

In order to provide an incentive for the truthful revelation of preferences, 10 percent of individuals were randomly paid one of their choices as in many other studies (for comparable methodologies and discussions, see, e.g., Harrison et al., 2002). This was done with a raffle ticket, which subjects took at the end of their tax filing and which indicated which choice, if any, would result in payment. To ensure credibility of the payments, we filled out money orders for the winning amounts on the spot in the presence of the participants, put them in labeled, pre-stamped envelopes and sealed the envelopes. The payment was guaranteed by the Federal Reserve Bank of Boston and individuals were informed that they could always return to the heads of the VITA site where the experiment was run to report any problems receiving the payments. Money orders were sent by mail to the winner's home address on the same day as the experiment (if $t=0$ ), or in one, six, or seven months, depending on the winner's choice. All payments were sent by mail to equate the transaction costs of sooner and later payments. ${ }^{7}$

\footnotetext{
${ }^{6}$ Individuals were additionally asked to make choices between the present $(t=0)$ and in six months $(\tau=6)$ in a third time frame. We opt to use only the $(t=0, \tau=1)$ and $(t=6, \tau=1)$ time frames in our primary analysis in order to calculate discounting and particularly present bias in a standard way (see Ashraf et al., 2006; Dohmen et al., 2006; Meier and Sprenger, 2010). Responses from the third time frame are added to the analysis as a robustness test. Results are qualitatively unchanged (see Section 3.3).

${ }^{7}$ If individuals expect to move in the next seven months, they might question the likelihood that their mail would be forwarded to their new address in a timely manner. As movers might therefore prefer payments in the present for logistical reasons and not for reasons related to their underlying time preference, we ask individuals
} 
The payment procedure therefore mimicked a front-end-delay design (Harrison et al., 2005b). The details of the payment procedure of the choice experiments were kept the same in the two years and participants were fully informed about the method of payment.

The multiple price list setup enables us to measure two aspects of individuals' time preferences. We measure: (1) individual discount factors and (2) whether individuals show a disproportionate preference for present rewards; that is, whether individuals are present-biased.

(1) Individual discount factor (IDF): We estimate monthly IDFs for the two time frames by looking at the point, $X^{*}$, at which individuals switch from opting for the smaller, sooner payment to the larger, later payment in a given price list. ${ }^{8}$ That is, a discount factor is taken from the last point at which an individual prefers the sooner, smaller payment. As this gives the point where sooner and later payments are approximately equally valued, $X^{*} \approx I D F \times Y$, we calculate $I D F=X^{*} / Y^{9}{ }^{9}$ For example, if an individual prefers $\$ 45$ today over $\$ 50$ in one month, but prefers $\$ 50$ in one month over $\$ 40$ today, we take $\$ 45$ as the switching point and the corresponding monthly discount factor of $45 / 50=0.90$.

Making these calculations for the two multiple price lists yields two discount measures, $I D F_{t, \tau}$, where $t$ refers to the sooner payment time (zero or six months) and $\tau$ refers to the delay length (one month): $I D F_{0,1}, I D F_{6,1}$. The average of these monthly discount factors, IDF, is used as the primary measure of discounting in our analysis. ${ }^{10}$

(2) Present Bias: The two time frames allow us to identify individuals who are dynamically

"Do you expect to move in the next 7 months?". However, whether individuals expect to move does not correlate with elicited time preferences and does not affect our results.

${ }^{8}$ For individuals with multiple switching points, we interpret the first switch point as the value of $X^{*}$. All results presented are maintained when eliminating individuals with multiple switch points from the analysis (see Section 3.3.)

${ }^{9}$ This formulation is equivalent to positing a linear utility function over the experimental outcomes and normalizing extra-experimental consumption (i.e., background consumption) to zero. Responses in time preference experiments may be affected by utility function curvature (see, e.g., Anderhub et al., 2001; Frederick et al., 2002; Andersen et al., 2008a). We do not have complimentary risk experiments as in Andersen et al. (2008a) or convex budgets as in Andreoni and Sprenger (2009a) to account for curvature. We do, however, ensure that our results are maintained when accounting for a survey measure of risk attitudes previously validated in a large representative sample (see Section 3.3).

${ }^{10}$ It should be noted that the price list methodology does not elicit point estimates of the IDF but rather ranges within which the discount factors lie. Because our analysis is focused on individual responses to the same experiment over time and not necessarily on precise estimation of the parameter measures, we do not control for the interval nature of the data in our analysis. 
inconsistent in the sense that they show a bias towards present payouts (see, e.g., Laibson, 1997; O’Donoghue and Rabin, 1999). By comparing individual choices in Time Frame $1(t=0$, $\tau=1)$ with Time Frame $2(t=6, \tau=1)$, we obtain a measure for whether individuals are dynamically inconsistent. If a person is present-biased, i.e. disproportionately prefers present payments, we would observe $I D F_{0,1}<I D F_{6,1} \cdot{ }^{11}$ We classify an individual as "Present-Biased $(=1)^{\prime}$ if they exhibit this pattern.

\section{$2.3 \quad$ Full Sample}

Column (1) in Table 1 shows summary statistics for the 1684 study observations. Participants earn, on average, approximately $\$ 16,000$ per year. They are around age 40 , female, AfricanAmerican, with less than a college education and have slightly less than 0.5 dependents. Around $10 \%$ of participants collected unemployment at some time during the previous calendar year (and so reported for tax filing purposes). Participants receive, on average, federal tax refunds of around $\$ 1,100$ and around $40 \%$ will have their refunds deposited directly in their bank account. Unlike age, income, dependents, unemployment and refund data which are precisely measured from individual tax returns, participants' gender, race and college experience were collected from an auxiliary demographic survey. A non-negligible proportion of observations, has at least one of these values missing. Missing values for the indicator variables related to gender, race and college experience are coded as the value of the majority and whether or not such values are missing is controlled for in our analysis.

[Table 1 about here.]

The subject pool, though non-standard, comes to the VITA site for reasons other than the experiment. This partially reduces the problem of subjects self-selecting into experiments (see Levitt and List, 2007). Individuals may, of course, choose not to participate in the experiment

\footnotetext{
${ }^{11}$ To see that present-biased individuals would exhibit this pattern of discounting, we consider one formulation of present bias, quasi-hyperbolic discounting. $I D F_{0,1}$ and $I D F_{6,1}$ capture both parameters of the quasihyperbolic model: $\beta$ and $\delta$. IDF $=\beta \delta^{\tau}$ if $t=0$ and $I D F^{\tau}=\delta^{\tau}$ if $t \neq 0$. This results in $I D F_{0,1}=\beta \delta$ and $I D F_{6,1}=\delta$, such that $I D F_{0,1}<I D F_{6,1}$ when an individual is present-biased $(\beta<1)$.
} 
once at the VITA site. Of all the individuals coming to the VITA site (2,366 in total), $71 \%$ elected to participate in the experiment.

Columns (2) and (3) in Table 1 report summary statistics for non-participants and $p$-values of $t$-tests for equal means between participants and non-participants. Examination of these statistics allows us to assess the axes upon which individuals may select into the study. Individuals appear to select on a variety of observable characteristics. Income, age, refund values, direct deposit, number of dependents and incomplete demographic survey responses all differ significantly between participants and non-participants. We control for all available socio-demographic characteristics (i.e., selection on observables) in our analysis of aggregate discounting (see Section 3.1).

Because there are 22 VITA sites around Boston, MA, each one is local to a specific neighborhood. VITA site attendee demographics are therefore similar over time. Columns (4) and (5) of Table 1 show summary statistics for participants in 2007 and 2008. Comparing the observable characteristics shows that individuals are slightly older and that slightly more participants are African-American, have lower refund values, are less likely to use direct deposit, and have some missing demographic information in 2008 relative to $2007 .{ }^{12}$ No other demographic differences are significant.

\subsection{Panel Sample}

Because the free tax preparation service is valuable, individuals return in subsequent years for further tax preparation assistance. Of the 890 study participants in 2007, we were able to measure time preferences again in 2008 for 250 returnees. ${ }^{13}$ A panel is created for these 250 individuals, allowing us to correlate individual preferences over time and to observe whether changes to income, unemployment status, family composition or future liquidity correlate with

\footnotetext{
${ }^{12}$ The slightly higher age, lower refund values and lower direct deposit usage of the 2008 sample is likely due to the 2008 Stimulus Payments which provided $\$ 300$ rebates to older social security recipients who would normally not file taxes. 10 percent of 2008 participants were over the age of 65 compared to only 4 percent of 2007 participants.

${ }^{13}$ Non-returnees either did not file taxes in a VITA site in Boston $(N=386)$, filed in another VITA site in Boston $(N=186)$, or filed taxes in the Roxbury VITA site, but did not participate in the experiment $(N=88)$.
} 
changes in measured preferences.

Table 2 reports summary statistics for returnees and examines differences in various characteristics between returnees and non-returnees. Substantial differences between returnees and non-returnees exist along the axes of income, age, race, education, and incomplete demographic survey information. Importantly, we find no evidence of attrition based on time preferences. Returnees and non-returnees have almost identical average levels of discounting and present bias.

The panel of returnees is clearly a selected sample. For the purposes of this study, selective attrition would be problematic if it was correlated with the stability of time preferences. One would hope to find a variable, plausibly orthogonal to the stability of preferences, correlated with the probability of attrition. It is helpful that there are 22 VITA sites around Boston. Tax assistance recipients generally use VITA sites local to their homes. We argue that the distance that an individual lived from the Roxbury VITA site in 2007 is plausibly orthogonal to time preference stability and may help to determine attrition.

We use tax filing information to obtain the zip code each individual used for their federal tax return. We calculate the direct line distance from the center of an individual's tax filing zip code to the center of Roxbury, MA 02119 where the VITA site is located. We additionally note whether an individual uses a post office box as opposed to a street address for tax-filing purposes. Panel $\mathrm{C}$ of Table 2 indicates that distance does indeed correlate with attrition. Individuals with zip codes more than 2 miles from Roxbury, MA were significantly less likely to return. Both returnees and non-returnees are equally likely to use a post office mailing address. We use distance as an exogenous determinant of sample attrition and use it to identify results in our panel analysis. We additionally account for the possibility that attrition could be based on 2007 demographics and 2007 time preferences (see Section 3.2).

[Table 2 about here.] 


\section{Results}

The results are presented in three broad sections. To begin, we analyze the stability of the distribution of estimated time preference parameters over the two years of the study at the aggregate level. In a second section, we restrict our attention to the 250 individuals who participated in the study twice. We discuss the extent to which individual responses correlate over time, and explore the sources of any instability. Robustness tests are presented in a third section.

\subsection{Temporal Stability in Aggregate Time Preferences}

When examining the same group of people through time, stability in the aggregate distribution of time preferences is a necessary condition for stability in individual time preferences. If the aggregate distribution of preferences is unstable, then individual preference parameters cannot be fixed. We examine two aggregate distributions of time preference parameters. First, because the sample pools are similar in the two years of the study, we examine the distribution of all 1684 study observations. Given the wide historical variation of time preference parameters obtained from different sample pools, this is a relevant avenue of exploration. Second, we examine the aggregate distribution of the 250 returnees who participated in the study twice.

Figure 1 plots histograms of IDF in the two years of the study for the two aggregate samples. The distributions are remarkably similar over time. For the full sample (Panel A), the average value for IDF is 0.79 in 2007 and 0.79 in 2008. For the returnees (Panel B), the average value for IDF is 0.80 in 2007 and 0.80 in 2008. Non-parametric Wilcoxon rank sum and sign rank tests fails to reject the null hypotheses of equal distributions over the two years: for the full sample $z=-0.176, p=0.86$ and for the returnee sample $z_{p}=0.067, p=0.95 .{ }^{14}$

[Figure 1 and 2 about here.]

\footnotetext{
${ }^{14}$ Unless otherwise noted, the statistic $z$ will refer to the test statistic of a Wilcoxon rank sum test and the statistic $z_{p}$ will refer to the test statistic of a paired Wilcoxon sign rank test. Additionally, returnees are not found to be different from non-returnees in the two years $(2007: z=-1.302, p=0.19 ; 2008: z=-0.831, p=0.41$ ).
} 
Figure 2 more closely examines the disaggregated measures of time preference: $I D F_{0,1}$ and $I D F_{6,1}$. Kernel estimates of the densities of these measures over the two years are provided. Echoing the result of Figure 1, the densities of each individual measure show remarkable stability over the two years of the study. Wilcoxon rank sum tests again fail to reject the null hypotheses of equal distributions over the two years. ${ }^{15}$ Apparent from Figure 2 is the substantial level of present bias in the samples. The density for $I D F_{0,1}$ has less mass at the higher levels of patience than that for $I D F_{6,1}$. Individuals are less likely to be patient in Time Frame 1 and more likely to be patient in Time Frame 2. In fact, substantial proportions of the samples are classified as being present-biased and this measure is stable as well. In 2007, 33 percent of all participants and 33 percent of returnees are classified as Present-Biased (=1) while in 2008, 35 percent of all participants and 32 percent of returnees are classified as Present-Biased (=1).

The obtained discount factor measures are, on average, low, but consistent with previous research, which tends to find low discount factors in experimental studies (see Frederick et al., 2002). The level of present bias observed in our sample is also comparable to previous research. Using similar techniques but different subject pools, Dohmen et al. (2006) and Ashraf et al. (2006) find a similar proportion of present-biased individuals, $28 \%$ and $27.5 \%$, respectively.

In Table 3 we test the hypothesis of stable aggregate preferences in regression. With ordinary least squares ${ }^{16}$, we regress IDF and Present-Biased (=1) on a constant and an indicator for the year of study being 2008:

$$
\text { Time Preference }_{i}=\beta_{0}+\beta_{1} \mathbf{1}(\text { Year }=2008)_{i}+\epsilon_{i}
$$

where Time Preference $_{i}$ is either IDF or Present-Biased (=1) and $\mathbf{1}\left(\text { Year }^{2}=2008\right)_{i}$ is an indicator for the study year being 2008.

\footnotetext{
${ }^{15}$ For $I D F_{0,1}: z=-0.086, p=0.93 ; z_{p}=0.281, p=0.78$. For $I D F_{6,1}: z=0.430 p=0.67 ; z_{p}=0.222, p=$ 0.82 .

${ }^{16}$ The least squares specification allows for ease of coefficient interpretation. However, IDF is censored and Present-Biased (=1) is binary and so would be more appropriately estimated with a tobit estimator and a probit or logit estimator, respectively. These estimates are provided in Appendix Table A1 (along with estimated demographic coefficients) and feature no qualitative differences.
} 
Tests of aggregate time preference stability are $t$-tests on the estimated coefficients $\hat{\beta}_{1}$. The size of $\hat{\beta}_{1}$ relative to $\hat{\beta}_{0}$ is an indicator of how much the mean level of time preferences changes over time. Columns (1), (2), (6) and (7) of Table 3 indicate that for the full sample and the sample of returnees $\hat{\beta}_{1}$ is small relative to its respective constant, $\hat{\beta}_{0}$, and is not significantly different from zero for both discounting and present bias. $R^{2}$ values from these regressions are virtually zero, as one would expect if the year of study had no explanatory power for the parameter values.

\section{[Table 3 about here.]}

Because our study represents the largest incentivized experimental study of time preferences, it may be of independent interest to examine the demographic correlates of obtained preference measures. Table 3, columns (3), (4), (8) and (9) present the demographic correlates of our time preference measures. In general, higher income, younger age and female gender are all associated with significantly higher IDF. In the full sample, college education and direct deposit usage are also associated with significantly higher IDF. ${ }^{17}$ Interestingly, refund values, as a measure of future liquidity, are uncorrelated with both discounting and present bias. In both samples, older individuals are found to be significantly less likely to be present-biased and college educated individuals are found to be significantly more likely to be present-biased. Though this last result is somewhat surprising, the remainder are in line with what one might expect in this sample.

Such correlations are also presented in aggregate studies of preferences such as Harrison et al. (2002) and Tanaka et al. (2009). For comparison, Tanaka et al. (2009) find that older and wealthier individuals are more patient and Harrison et al. (2002) find that more educated individuals are more patient. In both studies, gender and education are uncorrelated with discount factors. Tanaka et al. (2009) show virtually no correlation between present bias and

\footnotetext{
${ }^{17}$ Individuals using direct deposit, receive their federal tax refunds in 7-10 business days, substantially faster than mailed refund checks. Direct deposit usage may capture liquidity timing, but likely also measures financial sophistication and bank account holdership.
} 
demographic characteristics though, directionally, higher education is associated with more present bias and age is associated with less present bias, as in our results.

The demographic correlates of time preferences are largely similar across the full sample and the sample of returnees and the results are comparable to prior findings. Notable, however, are the low $R^{2}$ values. Though the demographic correlates of preferences may be of interest to researchers (and firms), these demographics explain less than $5 \%$ of the variance in time preferences. In columns (5) and (10) of Table 3 we include individual fixed effects for the sample of returnees. $R^{2}$ values increase dramatically. Roughly $60-70 \%$ of the variance in measured time preference parameters can be accounted for with the inclusion of individual fixed effects.

The aggregate distributions of time preferences are stable. Across all regressions, there is no impact of the year of study on measured preferences. Though a stable distribution could be obtained without individual stability, the observation that individual fixed effects explain much of the heterogeneity in measured preferences is suggestive of stability at the individual level. In the next section we focus our attention on the panel of individuals who participate in the study twice and examine preference stability at the individual level.

\subsection{Stability in Individual Time Preferences}

In this section we examine the stability of discounting and present bias at the individual level. The results are presented in two subsections. First, we examine the one-year correlations

in discount factors and present bias. Second, we identify instability in measured preferences and explore the relationship between instability, socio-demographics and economically relevant changes in income, future liquidity, employment and family composition.

\subsubsection{Temporal Stability of Time Preferences}

Of the 890 individuals who participated in 2007, 250 returned and participated again in 2008. For the sample of 250 returnees the one-year correlation in IDF is $\rho=0.401(p<0.01)$. The 
one-year correlation in the measure Present-Biased $(=1)$ is $\rho=0.160(p<0.05) .{ }^{18}$ Such one year correlations are significant and compare favorably to psychological benchmarks on the stability of personality traits (for a detailed discussion, see Section 4). However, such psychological stability studies rarely account for selective sample attrition. That is, it may be the case that only individuals with stable preferences elect to return to the VITA site in 2008. It may also be the case that socio-demographic characteristics reduce the obtained one-year correlations in preferences. These possibilities are explored in Table 4 .

In order to establish a baseline for evaluating the influence of demographics and selection on the stability of IDF, columns (1) and (4) of Table 4 estimate OLS regressions of IDF 2008 on $\mathrm{IDF}_{2007}$ and Present-Biased 2008 on Present-Biased 2007 with a constant. Columns (2) and (5) add all observable socio-demographic characteristics previously noted. Preferences remain significantly correlated over time and this correlation is virtually unchanged by the addition of socio-demographics.

[Table 4 about here.]

Columns (3) and (6) of Table 4 estimate Heckman 2-step procedures to control for selective attrition from the study. First, the inverse mills ratio is generated from a probit regression of non-attrition (i.e. selection). ${ }^{19}$ We model attrition as a function of observable socio-demographics, 2007 time preferences, and the distance an individual lives from the Roxbury VITA site. ${ }^{20}$ Under the assumption that distance is orthogonal to preference stability (as discussed in Section 2.4), column (3) and (6) identifies the temporal correlation in preferences controlling for stability-driven attrition. ${ }^{21}$ Controlling for sample attrition does little to the estimated correlations, though some precision is lost in the one-year correlation of present bias.

\footnotetext{
${ }^{18}$ When examining only individuals with unique price list switching points $(\mathrm{N}=203)$, the one-year correlation in IDF is $\rho=0.457(p<0.01)$ and the one year correlation in present bias is $\rho=0.241(p<0.01)$. The correlations for the different time frames separately is similar to the average. For $I D F_{0,1}, \rho=0.402, p<0.01$. For $I D F_{6,1}, \rho=0.328, p<0.01$.

${ }^{19}$ The inverse mills ratio is a sufficient statistic for the hazard of attrition (i.e., non-selection).

${ }^{20}$ We additionally include whether or not an individual used a PO Box for tax-filing purposes as a determinant of attrition. Distance is found to be a significant determinant of attrition. Full results of the Heckman selection equation are presented in Appendix Table A2.

${ }^{21}$ In the language of instrumental variables, distance 'instruments' for potentially endogenous selection.
} 
The results presented so far are suggestive of stable time preferences. Distribution of time preferences are stable over time, individual fixed effects explain large portions of the variance in measured preference parameters and the one-year correlations compare favorably with psychological findings. However, the results are not so one-sided. Thirty to forty percent of the variance in measured preferences is unaccounted for in our fixed effects regressions and the oneyear correlations are far from perfect. In the next section we attempt to explore the sources of this instability and whether there is any systematic changes in time preferences.

\subsubsection{Sources of Instability}

To explore changes in preferences over time, we first difference our time preference parameter estimates to create the variables: $\triangle I D F=I D F_{2008}-I D F_{2007}$ and $\Delta$ Present Bias $=$ PresentBiased (=1) 2008 - Present-Biased $(=1)_{2007}$. For the 250 returnees $\Delta I D F$ has mean .005 (s.e. $=$ .0146), indicating that the difference in discounting measures is on average small and tightly centered around zero (the $95 \%$ confidence interval for $\triangle I D F$ is $[-.0237, .0338]$ ). Figure 3 plots a histogram of $\triangle I D F$ indicating that the distribution is generally symmetric, centered around zero with large mass at or near zero, but a non-negligible number of extreme observations of large changes in measured patience. $\Delta$ Present Bias takes three possible values: -1, 0, 1. For the 250 returnees, around 69 percent $(\mathrm{n}=172)$ have $\Delta$ Present Bias $=0$, around 15 percent $(\mathrm{n}=38)$ have $\Delta$ Present Bias $=-1$ and 16 percent $(\mathrm{n}=40)$ have $\Delta$ Present Bias $=1$.

[Figure 3 about here.]

For the observations with changes in discounting or present bias, we are interested to know the source of this variation. In Table 5, we explore the determinants of instability in two ways. In columns (1) and (3), logit regression are presented where the dependent variable is 1 if an individual discount factor or present bias measure changed between 2007 and 2008. Columns (2) and (4) present similar ordered logit regression where the dependent variable is an ordered measure for the direction of the change in either discounting or present bias. These dependent variables are regressed on all socio-demographic characteristics as well as measured changes in 
income, unemployment status, number of dependents, and refund values. We recognize that this is not a comprehensive list of changes that could occur to these individuals. These data are, however, chosen for two reasons. First, changes to these states represent potentially large economic changes for low income individuals that are often argued to correlate with preferences (see e.g., Lawrance, 1991) and could affect current and future liquidity constraints and so could influence experimental responses. Second, these data are directly observable from individual tax-filings in subsequent years. ${ }^{22}$

[Table 5 about here.]

Importantly, given the socio-economic status of the sample, we observe individuals with substantial changes to income, numbers of dependents, unemployment and refund values. The median change in income was around \$1,359 or around 7\% higher income in 2008 compared to 2007. Around 26\% (65 of 250) of individuals experienced income increases of at least $30 \%$. Around $17 \%$ (43 of 250) of individuals experienced income decreases of at least 30\%. With respect to unemployment status, 220 of 250 show no change in unemployment while $12 \%$ (30 of 250) either cycle on to or off of unemployment in roughly equal proportions. With respect to the number of dependents 217 of 250 show no change in the number of dependents claimed on their tax filing, 6\% (15) show a decrease in dependents and around 7\% (18) show an increase in dependents. Changes in refund values are on average small, around 2\% (\$15) more in 2008 versus 2007. Around 28\% (69 of 250) of individuals experienced refund increases of at least $30 \%$ while $26 \%$ (64 of 250 ) experienced refund decreases of at least $30 \%{ }^{23}$

The results of Table 5 demonstrate that these large changes in economically relevant outcomes as well as levels of socio-demographics are not systematically related to instability and are virtually orthogonal to the direction of instability. Across 4 regressions, five coefficients are significant at the 10 percent level or higher. A $\chi^{2}$ test of zero slopes is not rejected in any of

\footnotetext{
${ }^{22}$ Though one would hope to obtain changes that are somehow exogenous, exogeneity is certainly debatable in this context. Individuals may choose to earn less money, withhold more taxes, have children, and apply for unemployment if fired.

${ }^{23} 10 \%$ (25 of 250 ) of individuals had refunds of $\$ 0$ in 2007 .
} 
the four regressions. Additionally, the panel analysis presented in Section 3.1 can also be interpreted as an exploration of whether changes in income, unemployment and family composition within individuals affect time preferences. Controlling for individual fixed effects in Table 3, we correlate changes in income, future liquidity, unemployment and family composition with changes in discounting and present bias. Apparent from Table 3 columns (5) and (10) is that observed changes in income, refund values, number of dependents and unemployment status are virtually uncorrelated with changes in discounting or present bias.

\subsection{Robustness Tests}

In this section we examine the robustness of our obtained results: first to an alternate measure of time preferences, second to controlling for individual risk attitudes, and third to restricting the sample to individuals with unique price list switching points.

In Table 6, we develop composite measures of time preference by including information from a third experimental time frame. In this third time frame, subjects were asked to make decisions between the present $(t=0)$ and six months from the study date $(\tau=6)$ (see instructions in Appendix A.2). This provides a third measure of monthly discounting: $I D F_{0,6} \cdot{ }^{24}$ We use this information to calculate a new average measure of discounting, $\overline{I D F}$, and a composite measure

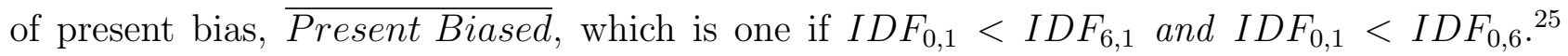
Panel A of Table 6 repeats the analysis of Tables 4 with these new measures. The results are very similar to those previously obtained.

[Table 6 about here.]

Individual responses in time preference choice experiments may be influenced by utility function curvature (Frederick et al., 2002; Andersen et al., 2008a). Under expected utility,

\footnotetext{
${ }^{24}$ Kernel density estimates of $I D F_{0,6}$ in 2007 and 2008 for the full sample and the sample of returnees show stability as well and are provided in Appendix Figure A1.

${ }^{25}$ Consider again a $\beta, \delta$ discounting model (e.g., Laibson, 1997) where $I D F_{0,1}=\beta \delta$ and $I D F_{0,6}=\beta^{1 / 6} \delta$. If $\beta<1$, then $I D F_{0,1}<I D F_{0,6}$. We account for the interval nature of measured discount factors when making this classification.
} 
curvature (i.e., diminishing marginal utility) generates risk aversion. As such, some experimental methodologies control for utility function curvature by eliciting risk preferences using secondary experiments (Andersen et al., 2008a) or by providing convex decision environments (Andreoni and Sprenger, 2009a). While our experimental environment was not conducive to either of these techniques we were able, however, to collect survey information on risk attitudes previously validated with a representative sample (Dohmen et al., 2005). Participants answer the following question on an 11 point scale: "How willing are you to take risks in general? (on a scale from "unwilling" to "fully prepared"). In Table 6 Panel B, we focus attention on individuals who answered this question in both years $(\mathrm{N}=136)$ and control for the change in risk attitudes over the two years. ${ }^{26}$ Andersen et al. (2008b) demonstrate stability in experimentally measured risk preferences. Our data echo this result. The one-year correlation in risk attitudes is substantial, $\rho=0.557(p<0.01)$, and the change in risk attitudes has mean 0.206 (s.e. 0.215). Controlling for changing risk attitudes, we again find that discounting and present bias are significantly correlated over time at the individual level.

Some individuals have more than one price list switch point, making it impossible to rationalize their responses with standard notions of time preference. ${ }^{27}$ Such subjects are normally either excluded from analysis, or their first switching point is the one examined. In the main part of our study we have taken the latter approach. In Table 6 Panel C, we repeat the analysis of Tables 4 using only the 203 individuals who have unique switching points in both years of the study. Because of this sample restriction criteria, we are unable to control for selective attrition as having a unique switch point in 2008 requires that an individual be a returnee. The results of Panel $\mathrm{C}$ of Table 6 are again consistent with our previous findings: discounting and present bias are significantly correlated over time at the individual level.

\footnotetext{
${ }^{26}$ Controlling for changing risk attitudes allows us to control for the possibility that a stable distribution of measured discount factors could be generated by unstable time preferences and equally unstable (but opposite) risk preferences.

${ }^{27}$ For example, at a low interest rate a person might prefer the sooner payment; at a moderate interest rate they switch to preferring the later payment; and then at a high interest rate they switch back to preferring the sooner payment. Interestingly, this inconsistency is correlated over time at the individual level. Results available from the authors on request.
} 


\section{Discussion}

A relevant issue in the discussion of preference stability is the correlation or stability that one might expect. Though the aggregate distributions of preferences are virtually unchanged over the two years and obtained correlations are significant, the correlations are far from perfect. Interpretation of the degree of temporal stability depends somewhat on one's expectations for our sample.

There is substantial discussion in the psychological literature as to whether the researcher's prior should be zero or perfect correlation (see e.g., Bem, 1972). A long-standing debate in psychology has generated a large amount of evidence indicating that the correlation of behavior in similar, though slightly distinct, situations rarely exceeds 0.2 to 0.3 (Mischel, 1968). Such "low" cross-situational correlations were taken as evidence against trait stability by situational psychologists. $^{28}$ Because our experiment is identical in the two years, this is not necessarily a good benchmark against which to measure stability. In psychological personality trait studies, the temporal correlation of 'Big Five' personality characteristics is found to be as high as 0.6 to 0.8 (Costa and McCrae, 1994). However, measures for such traits are generally obtained from aggregating hundreds of survey questions. Similar to single cross-situational measures, on smaller subsets or individual questions one could expect temporal correlations in the range of 0.2 to 0.3 (see e.g., Block, 1971; Jessor, 1983). ${ }^{29}$ Judged against this psychological benchmark, our temporal correlation of nearly 0.4 for IDF, obtained from two experimental measures, is high and our obtained correlation for present bias is in line with psychological findings.

In evaluating the size of the correlation found in our study, one also has to keep in mind that our participants differ substantially from participants in most previous studies. Most studies in psychology and in experimental economics use undergraduates as subjects while we conduct

\footnotetext{
${ }^{28}$ It has been shown that aggregate measures built up from various separate behaviors can yield substantially higher cross-situational correlations (for discussion and examples, see Epstein, 1979; Benz and Meier, 2008).

${ }^{29}$ These relevant studies are discussed in Costa and McCrae (1994) and Epstein (1979), who provide excellent surveys of stability studies in psychology. Both cited studies present median intertemporal correlation coefficients over a number of single personality measures and find that the majority of correlations are around or below 0.3 , specifically at longer time horizons.
} 
our choice experiments with low-to-moderate income individuals. These individuals' economic circumstances can, themselves, be very unstable. For example, as discussed in Section 3.2.2, $43 \%$ of our returnee sample had income changes of at least 30\%. Given these unstable circumstances, the estimated stability of time preferences is surprising. It is also important to note that substantial changes in circumstances, like income, employment, family composition and future liquidity, are virtually unrelated to changes in measured preferences.

Given that the one-year correlation in measured preferences compares favorably with prior research, one can discuss potential sources of stability. One possibility is that individuals simply recall their prior year choices and reproduce them. The correlation in measured time preferences is, however, unlikely to be driven by such recollection. First, the implemented choice experiments likely represent a minor event in participants' lives. The decisions are completed along with a host of other VITA site intake survey and tax information in preparation for tax filing. Second, the time delay in between experiments is large. The average delay between the 2007 and 2008 choice experiments was 363 days (s.d. 23). Third, subjects show limited ability to recall substantially more important information. Of the 250 returnees, 179 responded to a supplementary survey question asking whether or not they received the Earned Income Tax Credit in the prior year. 62.6 percent of respondents (112 of 179) either did not remember receiving the EITC or recalled incorrectly. Given that EITC values for the recipient returnees averaged around $\$ 1,400$ and that the VITA sites are advertised under the banner of helping claim important tax credits, recollection of EITC receipt should be much easier than recollection of choice experimental responses. Fourth, failure to recall EITC receipt or failure to correctly recall EITC receipt does not correlate with experimental consistency. ${ }^{30}$ Additionally, the temporal stability of the aggregate distribution of time preferences for individuals who participated in the choice experiments only once and therefore couldn't recollect their choice ( $N=1184$ in the Full Sample), also indicate that a willingness to be consistent cannot explain

\footnotetext{
${ }^{30}$ The correlation between not recalling and $\triangle I D F$ is -0.0045 and between not recalling and $\Delta$ Present Bias is -0.0089 . The correlation between recalling incorrectly and $\triangle I D F$ is -0.0069 and between recalling incorrectly and $\Delta$ Present Bias is 0.0108 . None of these correlations are significant.
} 
the stability.

Though the one-year correlations in measured preferences are notable, there are still substantial proportions of participants who show instability. As this instability cannot be explained by either socio-demographics or changes to income, unemployment, future liquidity, or family composition, the source of this instability remains largely unknown. One possibility is that changes in measured preferences are partially accounted for by measurement error. Indeed, given the structure of the employed multiple price list task, this is plausible. Switching one row lower in 2008 compared to 2007 implies a measured discount factor difference of between 0.04 and 0.14 (see Appendix A.2 for details). Perhaps with a more precise experimental measure higher correlations could be obtained. Another possibility is that short-lived liquidity and credit shocks separate from the annual changes we measure could be partially determining experimental responses. For example, if a subject receives an unexpected bill for which they need immediate funds, this could impact their experimental responses. Given the low socio-economic status of our observed sample, this is another plausible source of experimental instability. However, one would then expect to find that future liquidity measures such as refund values and changes in refund values would correlate with instability, which we do not. A third possible explanation is that there exist individuals with fundamentally unstable time preferences and that this instability is simply independent of any socio-demographic measure to which we have access.

\section{Conclusion}

Economic analysis of intertemporal decisions is predicated on the notion that time preferences are stable primitives. Though time preference stability is a standard assumption, relatively little research in economics exists on the topic and a large related literature in psychology disputes the notion that there are stable personality traits or preferences. In the largest experimental study of time preferences undertaken to date, we test time preference stability at both the aggregate and individual level. Using the same incentivized, intertemporal choice experiments 
and the same subject pool in two years, our results show that distributions of time preference parameters are stable over time, individual fixed effects explain large portions of the variance in parameter measures, and the one-year individual level correlations are high by psychological standards. However, the one-year correlations are far from perfect and 30 to 40 percent of the variance in preference parameters is unexplained. Notably, changes in time preferences are found to be largely independent of socio-demographics and changes to income, unemployment, family composition and future liquidity (all taken from individuals tax returns). Potential explanations for instability include measurement error and the possibility that some individuals have fundamentally unstable time preferences.

Finding the degree of stability in experimentally elicited time preferences we obtain supports two broad lines of economic research, one theoretical and one experimental. Much attention has been given to the low cross-situational correlation in behavior (Ross and Nisbett, 1991) and the wide variation in time preference parameter estimates resulting from experimental methods (Frederick et al., 2002). Our results indicate that, when rigorously controlling the sample pool and methodology, experimental procedures can yield stable aggregate parameter measures. This finding provides necessary support for theoretical developments based on aggregate assumptions of stable preferences. It also helps validate the current experimental trend towards correlating experimental time preference parameter measures with real-world behaviors (Ashraf et al., 2006; Meier and Sprenger, 2010). This line of research requires that experimentally measured preferences are stable enough to be usefully correlated with extra-experimental behavior. Given that these arguments rarely include precise estimates of marginal effects, significant correlation in measured preferences through time indicates that the obtained relationships may be more than just point-in-time correlations.

Finding the degree of instability we obtain also has implications for future research. First, in our discussion of instability, we note that the multiple price list methodology may be particularly sensitive to measurement error as small changes in price list switching points imply large changes in preferences. Future studies of stability of time preferences might find more stability if using 
more precise techniques for eliciting time preferences. Second, our results cannot rule out that there are some people with fundamentally unstable intertemporal preferences. Identifying these individuals, attempting to understand the source of their instability and modeling their decisions are important next steps. 


\section{References}

Anderhub, Vital, Werner Guth, Uri Gneezy, and Doron Sonsino, "On the interaction of risk and time preferences: An experimental study," German Economic Review, 2001, 2 (3), 239-253.

Andersen, Steffen, Glenn W. Harrison, Morten I. Lau, and Elisabet E. Rutstrom, "Eliciting Risk and Time Preferences," Econometrica, 2008, 76 (3), 583-618.

_ , _, , and _ , "Lost in State Space: Are Preferences Stable?," International Economic Review, $2008,49(3)$.

Andreoni, James and Charles Sprenger, "Estimating Time Preferences with Convex Budgets," Working Paper, 2009a.

Ashraf, Nava, Dean Karlan, and Wesley Yin, "Tying Odysseus to the Mast: Evidence from a Commitment Savings Product in the Philippines," Quarterly Journal of Economics, 2006, 121 (1), 635-672.

Bem, Daryl J., "Constructing Cross-Situational Consistencies in Behavior: Some Thoughts on Alker's Critique of Mischel," Journal of Personality, 1972, 40 (1), 17-26.

Benjamin, Daniel, James Choi, and Joshua Strickland, "Social Identity and Preferences," American Economic Review, 2009, Forthcoming.

Benz, Matthias and Stephan Meier, "Do People Behave in Experiments as in the Field? Evidence from Donations," Experimental Economics, 2008, 11 (3), 268-281.

Block, Jack, Lives Through Time, Berkeley, CA: Bancroft Books, 1971.

Burks, Stephan, Jeffrey Carpenter, Lorenz Goette, and Aldo Rustichini, "Cognitive skills affect economic preferences, strategic behavior, and job attachment," Proceedings of the National Academy of Science, 2009, 106 (19), 7745-7750.

Chabris, Christopher F., David Laibson, Carrie Morris, Jonathon Schuldt, and Dmitry Taubinsky, "Individual Laboratory-Measured Discount Rates Predict Field Behavior," Journal of Risk and Uncertainty, 2008, 37 (2-3), 237-269.

Coller, Maribeth and Melonie B. Williams, "Eliciting individual discount rates," Experimental Economics, 1999, 2, 107-127.

Costa, Paul T. and Robert R. McCrae, "Stability and Change in Personality from Adolescence through Adulthood," in Charles F. Halverson, Roy Geldolph A. Kohnstamm, and Martin, eds., The Developing Structure of Temperament and Personality from Infancy to Adulthood, Hillsdale, NJ: Erlbaum, 1994, chapter 7, pp. 139-150.

de Oliveira, Angela, Rachel Croson, and Catherine Eckel, "Are Preferences Stable Across Domains? An Experimental Investigation of Social Preferences in the Field," University of Texas at Dallas, CBEES Working Paper, 2009.

Dohmen, Thomas, Armin Falk, David Huffman, and Uwe Sunde, "Dynamic inconsistency predicts self-control problems in humans," Working Paper, 2006. 
${ }_{-},{ }_{-}, \ldots$, Juergen Schupp, and Gert G. Wagner, "Individual risk attitudes: New evidence from a large, representative, experimentally-validated survey," Working Paper, 2005.

Epstein, Seymour, "The Stability of Behavior: On Predicting Most of the People Much of the Time," Journal of Personality and Social Psychology, 1979, 37 (7), 1097-1125.

Fisher, Irving, The Theory of Interest as Determined by Impatience to Spend Income and Opportunity to Invest it, New York: The Macmillan Company, 1930.

Frederick, Shane, George Loewenstein, and Ted O'Donoghue, "Time discounting and time preference: A critical review," Journal of Economic Literature, 2002, 40 (2), 351-401.

Harrison, Glenn W., Morten I. Lau, and Elisabet E. Rutstrom, "Dynamic Consistency in Denmark: A Longitudinal Field Experiment," CEBR Discussion Paper 2005-06, 2005.

_, _, and Melonie B. Williams, "Estimating individual discount rates in Denmark: A field experiment," American Economic Review, 2002, 92 (5), 1606-1617.

_, _, Elisabet E. Rutstrom, and Melonie B. Williams, "Eliciting risk and time preferences using field experiments: Some methodological issues," in Jeffrey Carpenter, Glenn W. Harrison, and John A. List, eds., Field experiments in economics, Vol. Vol. 10 (Research in Experimental Economics), Greenwich and London: JAI Press, 2005.

Horowitz, John K., "A Test of Intertemporal Consistency," Journal of Economic Behavior and Organization, 1992, 17 (1), 171-82.

Ifcher, John and Homa Zarghamee, "Happiness and Myopia: Evidence from a RandomAssignment Experiment.," Working Paper, 2009.

Jessor, Richard, "The Stability of Change: Psychosocial Development From Adolescence to Young Adulthood," in David Magnusson and Vernon L. Allen, eds., Human Development: An Interactional Perspective, New York: Academic Press, 1983, pp. 321-341.

Laibson, David, "Golden Eggs and Hyperbolic Discounting," Quarterly Journal of Economics, 1997, $112(2), 443-477$.

Lawrance, Emily C., "Poverty and the Rate of Time Preference: Evidence from Panel Data," Journal of Political Economy, 1991, 99 (1), 54-77.

Levitt, Steven D. and John A. List, "What Do Laboratory Experiments Measuring Social Preferences Reveal About the Real World?," Journal of Economic Perspectives, 2007, 21 (2), 153-174.

McClure, Samuel, David Laibson, George Loewenstein, and Jonathan Cohen, "Separate neural systems value immediate and delayed monetary rewards," Science, 2004, 306, 503-507.

Meier, Stephan and Charles Sprenger, "Discounting and Defaulting: Evidence from Time Preference Experiments and Administrative Credit Data," Working Paper, 2009.

_ and _ , "Present-Biased Preferences and Credit Card Borrowing," American Economic Journal Applied Economics, 2010, 2 (1), 193-210.

Mischel, Walter, Personality and Assessment, New York: J. Wiley, 1968. 
_ , Yuichi Shoda, and Monica L. Rodriquez, "Delay of gratification in children," Science, 1989, 244 (4907), 933-938.

O'Donoghue, Ted and Matthew Rabin, "Doing it Now or Later," American Economic Review, 1999, 89 (1), 103-124.

Ross, Lee and Richard E. Nisbett, The Person and the Situation: Perspectives of Social Psychology, New York: McGraw-Hill, 1991.

Stigler, George J. and Gary S. Becker, "De Gustibus Non Est Disputandum," American Economic Review, 1977, 67 (2), 76-90.

Tanaka, Tomomi, Colin Camerer, and Quang Nguyen, "Risk and time preferences: Experimental and household data from Vietnam," American Economic Review, 2009, Forthcoming. 
Table 1: Summary Statistics for Participants and Non-Participants / for 2007 and 2008 Sample

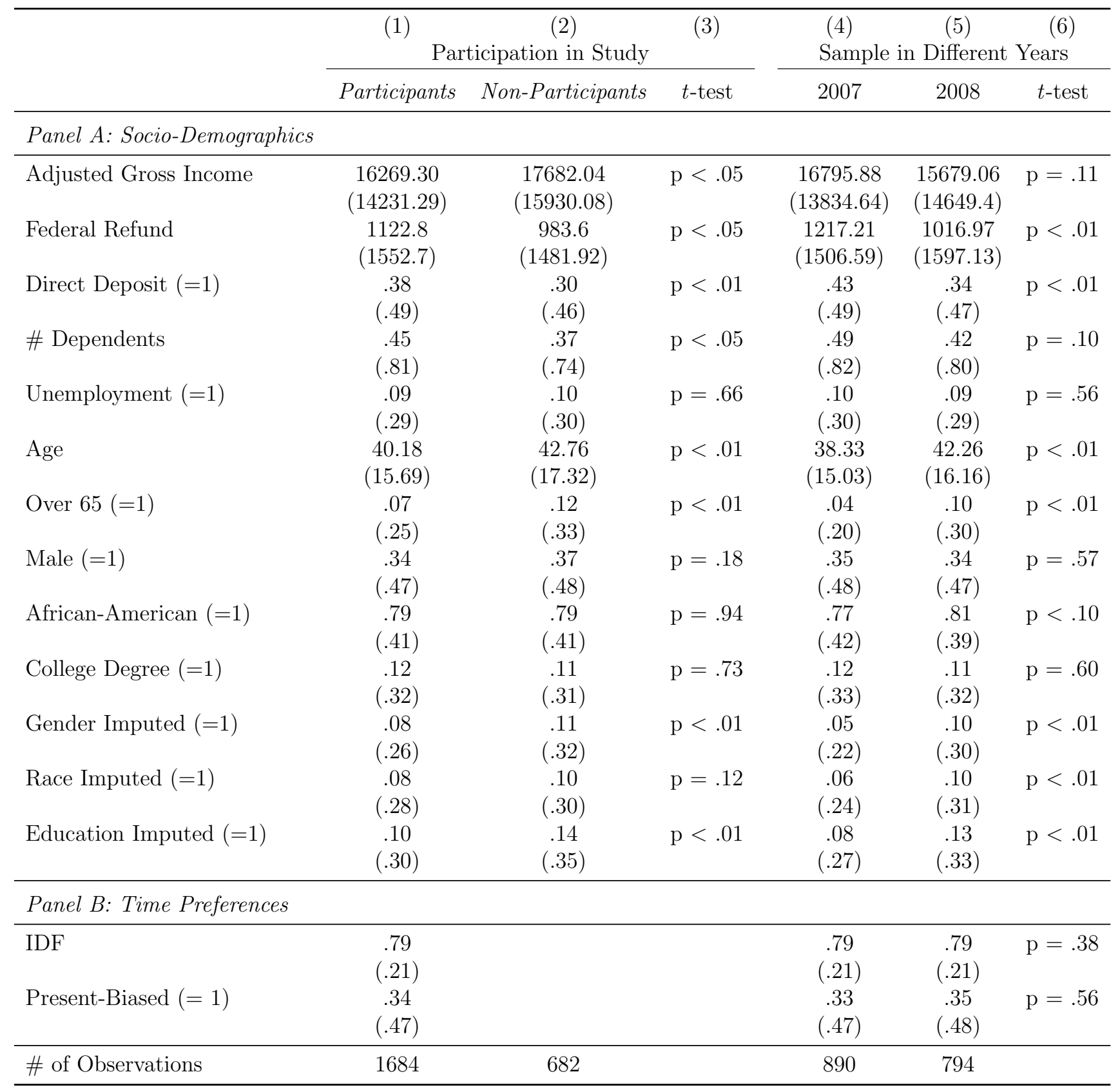

Notes: Table shows means of socio-demographics. Standard deviations in parenthesis. Column (3) shows $p$-values of $t$-tests for equal means between columns (1) and (2). Column (6) shows $p$-values of $t$-tests for equal means between columns (4) and (5). 
Table 2: Summary Statistics of Panel Sample

\begin{tabular}{|c|c|c|c|}
\hline & $\begin{array}{c}(1) \\
\text { Non-Returnee }\end{array}$ & $\begin{array}{c}(2) \\
\text { Returnee }\end{array}$ & $\begin{array}{c}(3) \\
t \text {-test }\end{array}$ \\
\hline \multicolumn{4}{|c|}{ Panel A: Socio-Demographics } \\
\hline Adjusted Gross Income & $\begin{array}{l}15458.43 \\
(13654.82)\end{array}$ & $\begin{array}{c}20219.75 \\
(13728.94)\end{array}$ & $p<.01$ \\
\hline Federal Refund & $\begin{array}{c}1183.42 \\
(1503.42)\end{array}$ & $\begin{array}{c}1303.72 \\
(1514.25)\end{array}$ & $\mathrm{p}=.29$ \\
\hline Direct Deposit $(=1)$ & $\begin{array}{l}.41 \\
(.49)\end{array}$ & $\begin{array}{l}.47 \\
(.50)\end{array}$ & $\mathrm{p}=.12$ \\
\hline Age & $\begin{array}{c}36.8 \\
(14.63)\end{array}$ & $\begin{array}{c}42.2 \\
(15.39)\end{array}$ & $p<.01$ \\
\hline Over $65(=1)$ & $\begin{array}{l}.03 \\
(.16)\end{array}$ & $\begin{array}{l}.09 \\
(.28)\end{array}$ & $p<.01$ \\
\hline Male $(=1)$ & $\begin{array}{l}.34 \\
(.47)\end{array}$ & $\begin{array}{l}.38 \\
(.49)\end{array}$ & $\mathrm{p}=.30$ \\
\hline African-American (=1) & $\begin{array}{l}.75 \\
(.43)\end{array}$ & $\begin{array}{l}.82 \\
(.38)\end{array}$ & $p<.05$ \\
\hline College Degree $(=1)$ & $\begin{array}{l}.10 \\
(.31)\end{array}$ & $\begin{array}{l}.16 \\
(.37)\end{array}$ & $p<.05$ \\
\hline Number of Dependents & $\begin{array}{l}.51 \\
(.85)\end{array}$ & $\begin{array}{l}.43 \\
(.72)\end{array}$ & $\mathrm{p}=.19$ \\
\hline Unemployment $(=1)$ & $\begin{array}{l}.10 \\
(.29)\end{array}$ & $\begin{array}{l}.10 \\
(.31)\end{array}$ & $\mathrm{p}=.70$ \\
\hline Gender Imputed $(=1)$ & $\begin{array}{l}.07 \\
(.25)\end{array}$ & $\begin{array}{l}.01 \\
(.11)\end{array}$ & $\mathrm{p}<.01$ \\
\hline Race Imputed (=1) & $\begin{array}{c}.08 \\
(.27)\end{array}$ & $\begin{array}{c}.03 \\
(.17)\end{array}$ & $\mathrm{p}<.01$ \\
\hline Education Imputed $(=1)$ & $\begin{array}{l}.10 \\
(.3) \\
\end{array}$ & $\begin{array}{c}.04 \\
(.19) \\
\end{array}$ & $\mathrm{p}<.01$ \\
\hline \multicolumn{4}{|l|}{ Panel B: Time Preferences } \\
\hline $\mathrm{IDF}_{2007}$ & $\begin{array}{l}.78 \\
(.21)\end{array}$ & $\begin{array}{l}.80 \\
(.22)\end{array}$ & $\mathrm{p}=.25$ \\
\hline Present-Biased $(=1)_{2007}$ & $\begin{array}{c}.33 \\
(.47) \\
\end{array}$ & $\begin{array}{c}.33 \\
(.47) \\
\end{array}$ & $\mathrm{p}=.89$ \\
\hline \multicolumn{4}{|l|}{ Panel C: Distance } \\
\hline Less than 1 mile & $\begin{array}{l}.31 \\
(.46)\end{array}$ & $\begin{array}{l}.36 \\
(.48)\end{array}$ & $\mathrm{p}=.19$ \\
\hline 1 - 2 Miles & $\begin{array}{c}.34 \\
(.47)\end{array}$ & $\begin{array}{c}.37 \\
(.48)\end{array}$ & $\mathrm{p}=.33$ \\
\hline More than 2 miles & $\begin{array}{l}.35 \\
(.48)\end{array}$ & $\begin{array}{l}.27 \\
(.44)\end{array}$ & $p<.05$ \\
\hline PO Box $(=1)$ & $\begin{array}{c}.02 \\
(.15) \\
\end{array}$ & $\begin{array}{c}.02 \\
(.13) \\
\end{array}$ & $\mathrm{p}=.58$ \\
\hline \# of Observations & 640 & 250 & \\
\hline
\end{tabular}

Notes: Table shows means of variables in 2007. Standard deviations in parenthesis. Column (3) shows $p$-values of $t$-tests for equal means between column (1) and (2). 


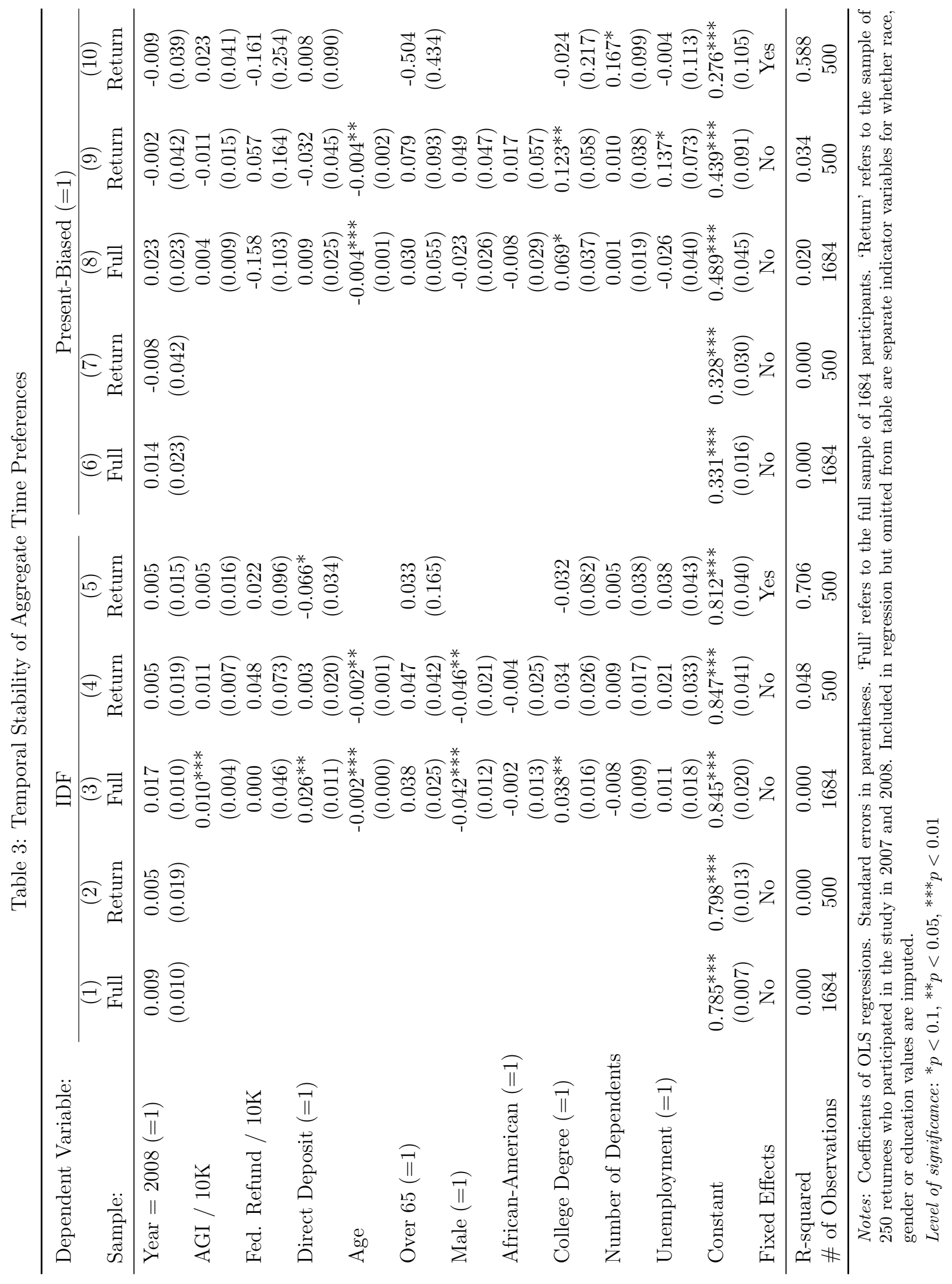


Table 4: Temporal Stability of Individual Time Preferences

\begin{tabular}{|c|c|c|c|c|c|c|}
\hline \multirow[t]{2}{*}{ Dependent Variable: } & \multicolumn{3}{|c|}{$\mathrm{IDF}_{2008}$} & \multicolumn{3}{|c|}{ Present-Biased $(=1)_{2008}$} \\
\hline & $\begin{array}{l}(1) \\
\text { OLS }\end{array}$ & $\begin{array}{l}(2) \\
\text { OLS }\end{array}$ & $\begin{array}{c}(3) \\
\text { Heckman }\end{array}$ & $\begin{array}{l}(4) \\
\text { OLS }\end{array}$ & $\begin{array}{l}(5) \\
\text { OLS }\end{array}$ & $\begin{array}{c}(6) \\
\text { Heckman }\end{array}$ \\
\hline $\mathrm{IDF}_{2007}$ & $\begin{array}{c}0.383^{* * *} \\
(0.056)\end{array}$ & $\begin{array}{c}0.376^{* * *} \\
(0.059)\end{array}$ & $\begin{array}{c}0.368^{* * *} \\
(0.071)\end{array}$ & & & \\
\hline Present Biased $_{2007}$ & & & & $\begin{array}{c}0.159^{* *} \\
(0.062)\end{array}$ & $\begin{array}{c}0.128^{* *} \\
(0.063)\end{array}$ & $\begin{array}{l}0.121^{*} \\
(0.064)\end{array}$ \\
\hline AGI / 10K & & $\begin{array}{c}0.004 \\
(0.010)\end{array}$ & $\begin{array}{c}0.002 \\
(0.016)\end{array}$ & & $\begin{array}{l}-0.017 \\
(0.023)\end{array}$ & $\begin{array}{l}-0.034 \\
(0.035)\end{array}$ \\
\hline Fed. Refund / 10K & & $\begin{array}{l}-0.028 \\
(0.119)\end{array}$ & $\begin{array}{l}-0.049 \\
(0.164)\end{array}$ & & $\begin{array}{c}0.031 \\
(0.284)\end{array}$ & $\begin{array}{l}-0.109 \\
(0.365)\end{array}$ \\
\hline Direct Deposit $(=1)$ & & $\begin{array}{c}0.008 \\
(0.026)\end{array}$ & $\begin{array}{c}0.006 \\
(0.029)\end{array}$ & & $\begin{array}{l}-0.028 \\
(0.062)\end{array}$ & $\begin{array}{l}-0.046 \\
(0.069)\end{array}$ \\
\hline Age & & $\begin{array}{l}-0.001 \\
(0.001)\end{array}$ & $\begin{array}{l}-0.001 \\
(0.002)\end{array}$ & & $\begin{array}{r}-0.004^{*} \\
(0.002)\end{array}$ & $\begin{array}{r}-0.006^{*} \\
(0.003)\end{array}$ \\
\hline Over $65(=1)$ & & $\begin{array}{c}0.069 \\
(0.055)\end{array}$ & $\begin{array}{c}0.059 \\
(0.075)\end{array}$ & & $\begin{array}{c}0.128 \\
(0.132)\end{array}$ & $\begin{array}{c}0.064 \\
(0.170)\end{array}$ \\
\hline Male $(=1)$ & & $\begin{array}{c}0.031 \\
(0.028)\end{array}$ & $\begin{array}{c}0.029 \\
(0.029)\end{array}$ & & $\begin{array}{c}0.072 \\
(0.067)\end{array}$ & $\begin{array}{c}0.067 \\
(0.067)\end{array}$ \\
\hline African-American (=1) & & $\begin{array}{c}0.007 \\
(0.033)\end{array}$ & $\begin{array}{c}0.001 \\
(0.044)\end{array}$ & & $\begin{array}{l}-0.003 \\
(0.080)\end{array}$ & $\begin{array}{l}-0.037 \\
(0.097)\end{array}$ \\
\hline College Degree $(=1)$ & & $\begin{array}{c}0.019 \\
(0.034)\end{array}$ & $\begin{array}{c}0.016 \\
(0.037)\end{array}$ & & $\begin{array}{l}0.169^{* *} \\
(0.082)\end{array}$ & $\begin{array}{l}0.148^{*} \\
(0.089)\end{array}$ \\
\hline Number of Dependents & & $\begin{array}{c}0.027 \\
(0.026)\end{array}$ & $\begin{array}{c}0.032 \\
(0.038)\end{array}$ & & $\begin{array}{c}0.014 \\
(0.061)\end{array}$ & $\begin{array}{c}0.047 \\
(0.082)\end{array}$ \\
\hline Unemployment $(=1)$ & & $\begin{array}{c}0.015 \\
(0.041)\end{array}$ & $\begin{array}{c}0.015 \\
(0.040)\end{array}$ & & $\begin{array}{l}0.175^{*} \\
(0.099)\end{array}$ & $\begin{array}{l}0.175^{*} \\
(0.099)\end{array}$ \\
\hline Constant & $\begin{array}{c}0.498^{* * *} \\
(0.046)\end{array}$ & $\begin{array}{c}0.498^{* * *} \\
(0.073)\end{array}$ & $\begin{array}{c}0.561 \\
(0.350)\end{array}$ & $\begin{array}{c}0.268^{* * *} \\
(0.036)\end{array}$ & $\begin{array}{c}0.413^{* * *} \\
(0.124)\end{array}$ & $\begin{array}{c}0.783 \\
(0.626)\end{array}$ \\
\hline Selection Equation & No & No & Yes & No & No & Yes \\
\hline R-squared & 0.161 & 0.175 & & 0.026 & 0.083 & \\
\hline \# of Observations & 250 & 250 & 890 & 250 & 250 & 890 \\
\hline Censored Observations & - & - & 640 & - & - & 640 \\
\hline Uncensored Observations & - & - & 250 & - & - & 250 \\
\hline
\end{tabular}

Notes: Coefficients of OLS and Heckman 2-Step regressions. Standard errors in parentheses. Full results of the Heckman selection equation are presented in Appendix Table A2. All socio-demographics are 2007 values. Included in regression but omitted from table are separate indicator variables for whether race, gender or education values are imputed.

Level of significance: ${ }^{*} p<0.1,{ }^{* *} p<0.05,{ }^{* * *} p<0.01$ 
Table 5: Determinants of Instability

\begin{tabular}{|c|c|c|c|c|}
\hline Dependent Variable: & $\begin{array}{c}\text { IDF } \\
\text { Changed }(=1)\end{array}$ & $\begin{array}{l}\text { IDF Direction } \Delta \\
(-1,0,1)\end{array}$ & $\begin{array}{l}\text { Present-Biased } \\
\text { Changed }(=1)\end{array}$ & $\begin{array}{c}\text { Present Bias Direction } \Delta \\
(-1,0,1)\end{array}$ \\
\hline & (1) & (2) & (3) & (4) \\
\hline & Logit & Ord. Logit & Logit & Ord. Logit \\
\hline \multirow[t]{2}{*}{ AGI / 10K } & -0.097 & -0.041 & 0.056 & -0.009 \\
\hline & $(0.115)$ & $(0.089)$ & $(0.113)$ & $(0.101)$ \\
\hline \multirow[t]{2}{*}{ Fed Refund / 10K } & 2.078 & 1.602 & 1.652 & 0.286 \\
\hline & $(1.545)$ & $(1.220)$ & $(1.417)$ & $(1.363)$ \\
\hline \multirow[t]{2}{*}{ Direct Deposit $(=1)$} & 0.074 & -0.057 & 0.163 & -0.007 \\
\hline & $(0.316)$ & $(0.251)$ & $(0.289)$ & $(0.275)$ \\
\hline \multirow[t]{2}{*}{ Age } & $-0.028 * *$ & 0.000 & 0.003 & -0.003 \\
\hline & $(0.012)$ & $(0.010)$ & $(0.011)$ & $(0.011)$ \\
\hline \multirow[t]{2}{*}{ Over $65(=1)$} & 0.742 & -0.199 & -0.427 & 0.234 \\
\hline & $(0.647)$ & $(0.525)$ & $(0.645)$ & $(0.575)$ \\
\hline \multirow[t]{2}{*}{ Male $(=1)$} & $0.642^{*}$ & $0.455^{*}$ & -0.078 & 0.224 \\
\hline & $(0.348)$ & $(0.271)$ & $(0.312)$ & $(0.294)$ \\
\hline \multirow[t]{2}{*}{ African-American $(=1)$} & 0.438 & -0.072 & 0.218 & -0.036 \\
\hline & $(0.397)$ & $(0.319)$ & $(0.378)$ & $(0.354)$ \\
\hline \multirow[t]{2}{*}{ College Degree $(=1)$} & -0.176 & -0.011 & -0.349 & 0.226 \\
\hline & $(0.406)$ & $(0.332)$ & $(0.393)$ & $(0.369)$ \\
\hline \multirow[t]{2}{*}{ Number of Dependents } & -0.079 & -0.178 & 0.083 & 0.168 \\
\hline & $(0.307)$ & $(0.253)$ & $(0.292)$ & $(0.278)$ \\
\hline \multirow[t]{2}{*}{ Unemployment $(=1)$} & $1.575^{*}$ & 0.220 & 0.508 & 0.041 \\
\hline & $(0.865)$ & $(0.544)$ & $(0.590)$ & $(0.579)$ \\
\hline \multirow[t]{2}{*}{$\Delta(\mathrm{AGI} / 10 \mathrm{~K})$} & -0.225 & 0.024 & -0.170 & 0.097 \\
\hline & $(0.172)$ & $(0.131)$ & $(0.154)$ & $(0.140)$ \\
\hline \multirow[t]{2}{*}{$\Delta($ Fed Refund / 10K $)$} & 0.418 & 0.024 & 1.556 & -0.371 \\
\hline & $(1.036)$ & $(0.745)$ & $(1.026)$ & $(0.873)$ \\
\hline \multirow[t]{2}{*}{$\Delta$ Number of Dependents } & 0.216 & -0.312 & $0.691^{*}$ & 0.544 \\
\hline & $(0.432)$ & $(0.326)$ & $(0.389)$ & $(0.347)$ \\
\hline \multirow[t]{2}{*}{$\Delta$ Unemployment $(=1)$} & -0.332 & 0.173 & 0.187 & -0.078 \\
\hline & $(0.607)$ & $(0.460)$ & $(0.516)$ & $(0.507)$ \\
\hline \multirow[t]{2}{*}{ Constant } & $1.325^{* *}$ & & $-1.218^{* *}$ & \\
\hline & $(0.631)$ & & $(0.587)$ & \\
\hline Log-Likelihood & -136.693 & -268.796 & -156.119 & -224.153 \\
\hline Pseudo R-squared & 0.078 & 0.015 & 0.051 & 0.018 \\
\hline \multirow[t]{2}{*}{ Zero Slopes $\chi^{2}$} & 23.04 & 8.22 & 16.70 & 8.13 \\
\hline & $(\mathrm{p}=0.11)$ & $(p=0.96)$ & $(\mathrm{p}=0.41)$ & $(\mathrm{p}=0.96)$ \\
\hline $\mathrm{N}$ & 250 & 250 & 250 & 250 \\
\hline
\end{tabular}

Notes: Logit regressions in columns (1) and (3). Ordered logit regressions in columns (2) and (4). Changed (=1) is a variable which takes the value 1 if an individuals' IDF (column (1)) or present bias indicator (column (3)) changed between 2007 and 2008. The Direction $\Delta$ variables capture the direction of these changes. They are calculated as IDF Direction $\Delta=$ $\operatorname{sign}\left(I D F_{2008}-I D F_{2007}\right)$ and Present Bias Direction $\Delta=\operatorname{sign}\left(\right.$ Present Biased $2008-$ Present Biased $\left._{2007}\right)$. For example, IDF Direction $\Delta$ is coded as -1 if an individual had lower IDF in 2008 compared 2007, 0 if there was no change, and 1 if an individual had a higher IDF in 2008 compared to 2007. Standard errors in parentheses. All socio-demographics are 2007 values. Changes in socio-demographics are 2008 values minus 2007 values. Included in regression but omitted from table are separate indicator variables for whether race, gender or education values are imputed. Imputed gender not included in columns (1) and (3) as all three individuals with imputed gender had IDF Changed (=1) and Present-Biased Changed (=1). Level of significance: ${ }^{*} p<0.1,{ }^{* *} p<0.05,{ }^{* * *} p<0.0131$ 
Table 6: Robustness Tests

\begin{tabular}{|c|c|c|c|c|c|c|}
\hline & (1) & $(2)$ & (3) & $(4)$ & (5) & $(6)$ \\
\hline Method: & OLS & OLS & Heckman & OLS & OLS & Heckman \\
\hline Control Variables: & No & Yes & Yes & No & Yes & Yes \\
\hline Selection Equation: & No & No & Yes & No & No & Yes \\
\hline \multicolumn{7}{|c|}{ Panel A: Composite Time Preference Measures } \\
\hline Dependent Variable: & & $\overline{I D F}_{2008}$ & & $\overline{\text { Presen }}$ & - Biased & $(=1)_{2008}$ \\
\hline$\overline{I D F}_{2007}$ & $\begin{array}{c}0.387^{* * * *} \\
(0.055)\end{array}$ & $\begin{array}{c}0.381^{* * *} \\
(0.059)\end{array}$ & $\begin{array}{c}0.379^{* * *} \\
(0.069)\end{array}$ & & & \\
\hline 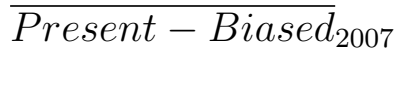 & & & & $\begin{array}{c}0.165^{* * *} \\
(0.063)\end{array}$ & $\begin{array}{l}0.122^{*} \\
(0.065)\end{array}$ & $\begin{array}{l}0.119^{*} \\
(0.064)\end{array}$ \\
\hline Constant & $\begin{array}{c}0.520^{* * *} \\
(0.047)\end{array}$ & $\begin{array}{c}0.514^{* * *} \\
(0.066)\end{array}$ & $\begin{array}{c}0.533^{* *} \\
(0.269)\end{array}$ & $\begin{array}{c}0.212^{* * *} \\
(0.031)\end{array}$ & $\begin{array}{c}0.419^{* * *} \\
(0.114)\end{array}$ & $\begin{array}{c}0.615 \\
(0.553)\end{array}$ \\
\hline $\mathrm{N}$ & 250 & 250 & 250 & 250 & 250 & 250 \\
\hline \multicolumn{7}{|c|}{ Panel B: Inclusion of Risk Attitudes } \\
\hline Dependent Variable: & & $\mathrm{IDF}_{2008}$ & & Presel & t-Biased ( & $=1)_{2008}$ \\
\hline $\mathrm{IDF}_{2007}$ & $\begin{array}{c}0.393^{* * *} \\
(0.078)\end{array}$ & $\begin{array}{c}0.362^{* * *} \\
(0.084)\end{array}$ & $\begin{array}{c}0.333^{* *} \\
(0.137)\end{array}$ & & & \\
\hline 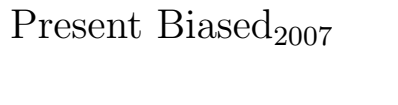 & & & & $\begin{array}{c}0.236^{* * * *} \\
(0.084)\end{array}$ & $\begin{array}{c}0.241^{* * *} \\
(0.087)\end{array}$ & $\begin{array}{c}0.255^{* * *} \\
(0.088)\end{array}$ \\
\hline$\Delta$ Risk Measure & $\begin{array}{c}0.000 \\
(0.006)\end{array}$ & $\begin{array}{c}0.002 \\
(0.007)\end{array}$ & $\begin{array}{c}0.002 \\
(0.007)\end{array}$ & $\begin{array}{c}0.016 \\
(0.016)\end{array}$ & $\begin{array}{c}0.023 \\
(0.017)\end{array}$ & $\begin{array}{c}0.023 \\
(0.016)\end{array}$ \\
\hline Constant & $\begin{array}{c}0.484^{* * *} \\
(0.066)\end{array}$ & $\begin{array}{c}0.539^{* * *} \\
(0.100)\end{array}$ & $\begin{array}{c}0.678 \\
(0.550)\end{array}$ & $\begin{array}{c}0.272^{* * *} \\
(0.051)\end{array}$ & $\begin{array}{c}0.369^{* *} \\
(0.170)\end{array}$ & $\begin{array}{l}-0.025 \\
(0.713)\end{array}$ \\
\hline $\mathrm{N}$ & 136 & 136 & 136 & 136 & 136 & 136 \\
\hline \multicolumn{7}{|c|}{ Panel C: Restricted Sample of Unique Switchers } \\
\hline Dependent Variable: & & $\mathrm{IDF}_{2008}$ & & Presel & t-Biased ( & $=1)_{2008}$ \\
\hline $\mathrm{IDF}_{2007}$ & $\begin{array}{c}0.447 * * * \\
(0.061)\end{array}$ & $\begin{array}{c}0.428^{* * *} \\
(0.066)\end{array}$ & & & & \\
\hline Present Biased 2007 & & & & $\begin{array}{c}0.240^{* * *} \\
(0.068)\end{array}$ & $\begin{array}{c}0.185^{* * *} \\
(0.071)\end{array}$ & \\
\hline Constant & $\begin{array}{c}0.435^{* * *} \\
(0.050)\end{array}$ & $\begin{array}{c}0.446^{* * *} \\
(0.081)\end{array}$ & & $\begin{array}{c}0.236^{* * *} \\
(0.038)\end{array}$ & $\begin{array}{c}0.493^{* * *} \\
(0.136)\end{array}$ & \\
\hline $\mathrm{N}$ & 203 & 203 & & 203 & 203 & \\
\hline
\end{tabular}

Notes: Coefficients of OLS and Heckman 2-Step regressions. Standard errors in parentheses. Full results of the Heckman selection equation are presented in Appendix Table A2. Control variables are 2007 sociodemographics as in Tables 3 and 4 .

Level of significance: ${ }^{*} p<0.1,{ }^{* *} p<0.05,{ }^{* * *} p<0.01$ 
Figure 1: Aggregate Discounting Distributions Through Time

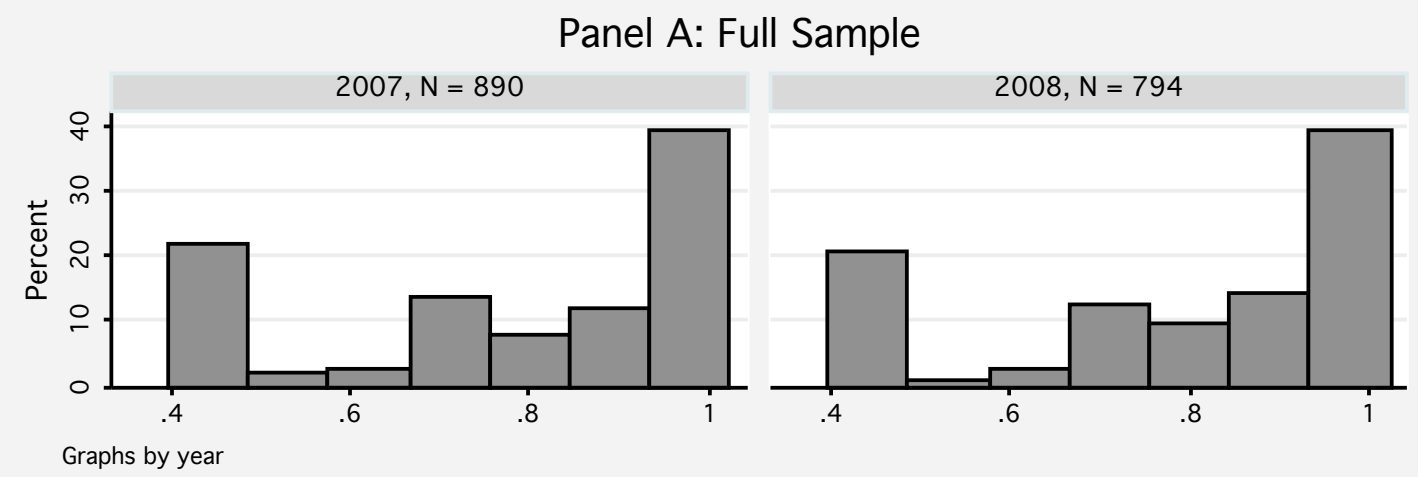

Panel B: Returnee Sample

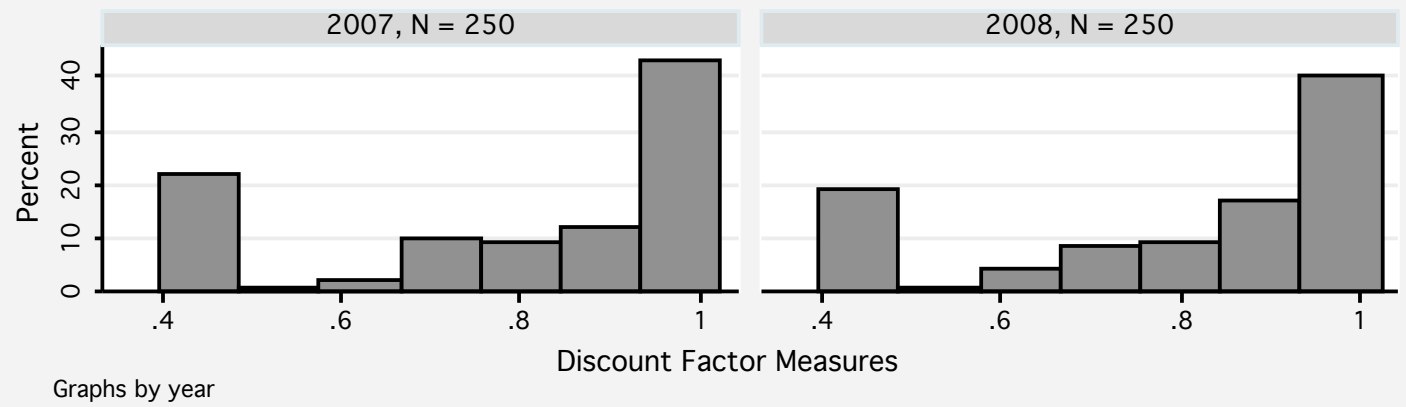

Note: Panel A presents histograms of IDF for the full sample of all participants separately for 2007 (N=890) and $2008(\mathrm{~N}=794)$. Wilcoxon rank-sum test $\left(H_{0}\right.$ : equal distributions over time): $z=-0.176, p=0.86$. Panel B presents histograms of IDF for the sample of returnees separately for $2007(\mathrm{~N}=250)$ and $2008(\mathrm{~N}=250)$. Paired Wilcoxon sign rank test $\left(H_{0}\right.$ : equal distributions over time): $z_{p}=0.067, p=0.95$. Additionally, returnees are found to be no different from non-returnees in the two years $(2007: z=-1.302, p=0.19 ; 2008$ : $z=-0.831, p=0.41)$. 


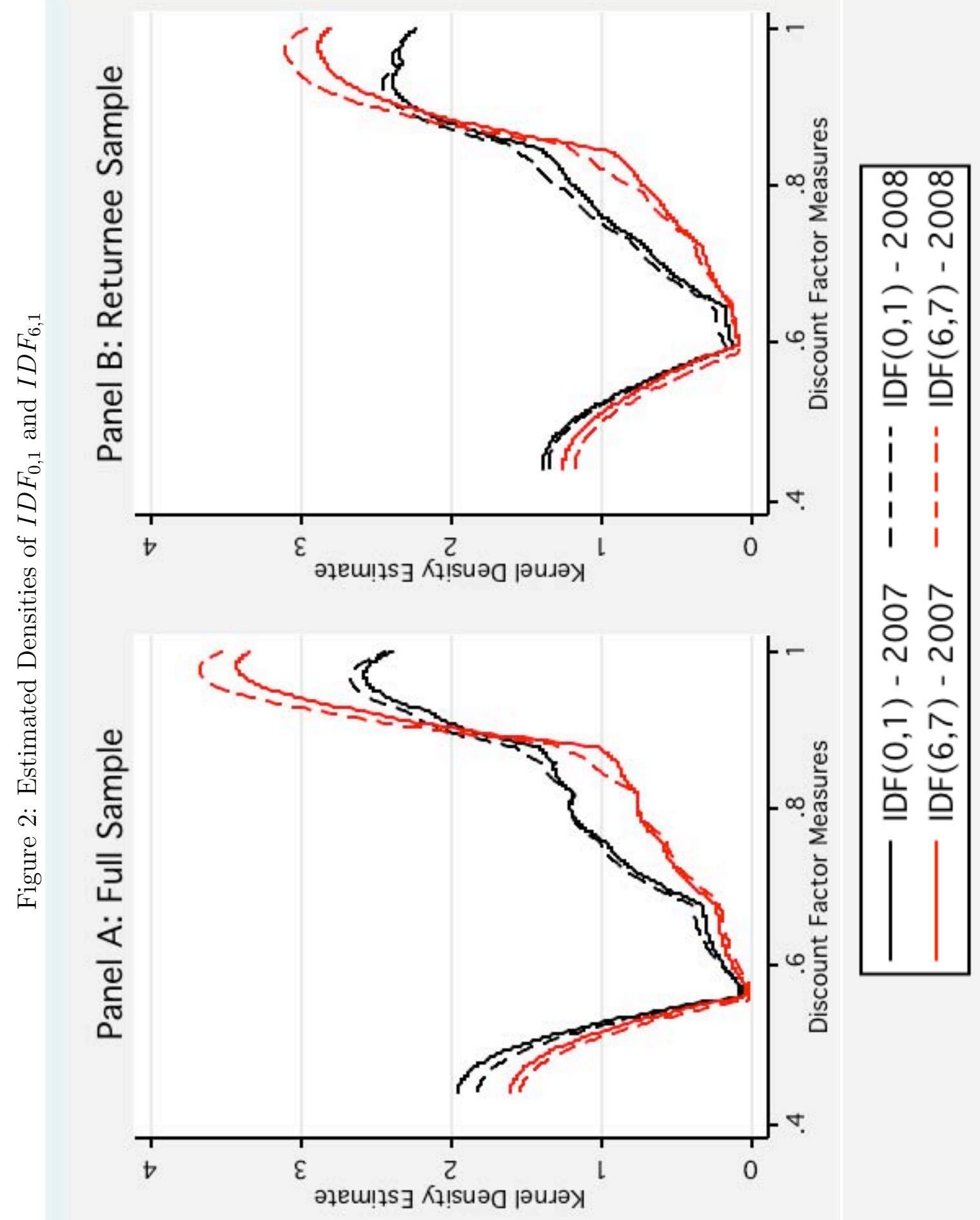

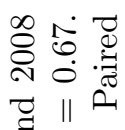

चี

จิ

$\infty$ 畄 II

乙造这

$4 \| \infty$

จำ ॥

N $=8$

ธิด

근즈유.ำ.

ث

西之

论

윰

.

矛 1130

吃

\%ี $0^{\infty}$ สี

पे

을 $\|$

द्व

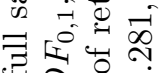

츠잉

ఫे द्व

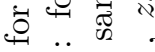

웜

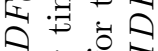

$\forall$ 눙

चै ठำ

등

棺

츨

पे

क

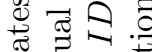

켱엉

记

螘

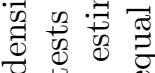

$+0$

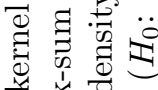

站

苟 $\vec{\Xi}$

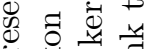

ㄹ. 상 क

$\varangle$ 记

षे क.

๘ี.

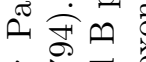

i웡

之足完 
Figure 3: Change in Discounting Measure: $\Delta$ IDF

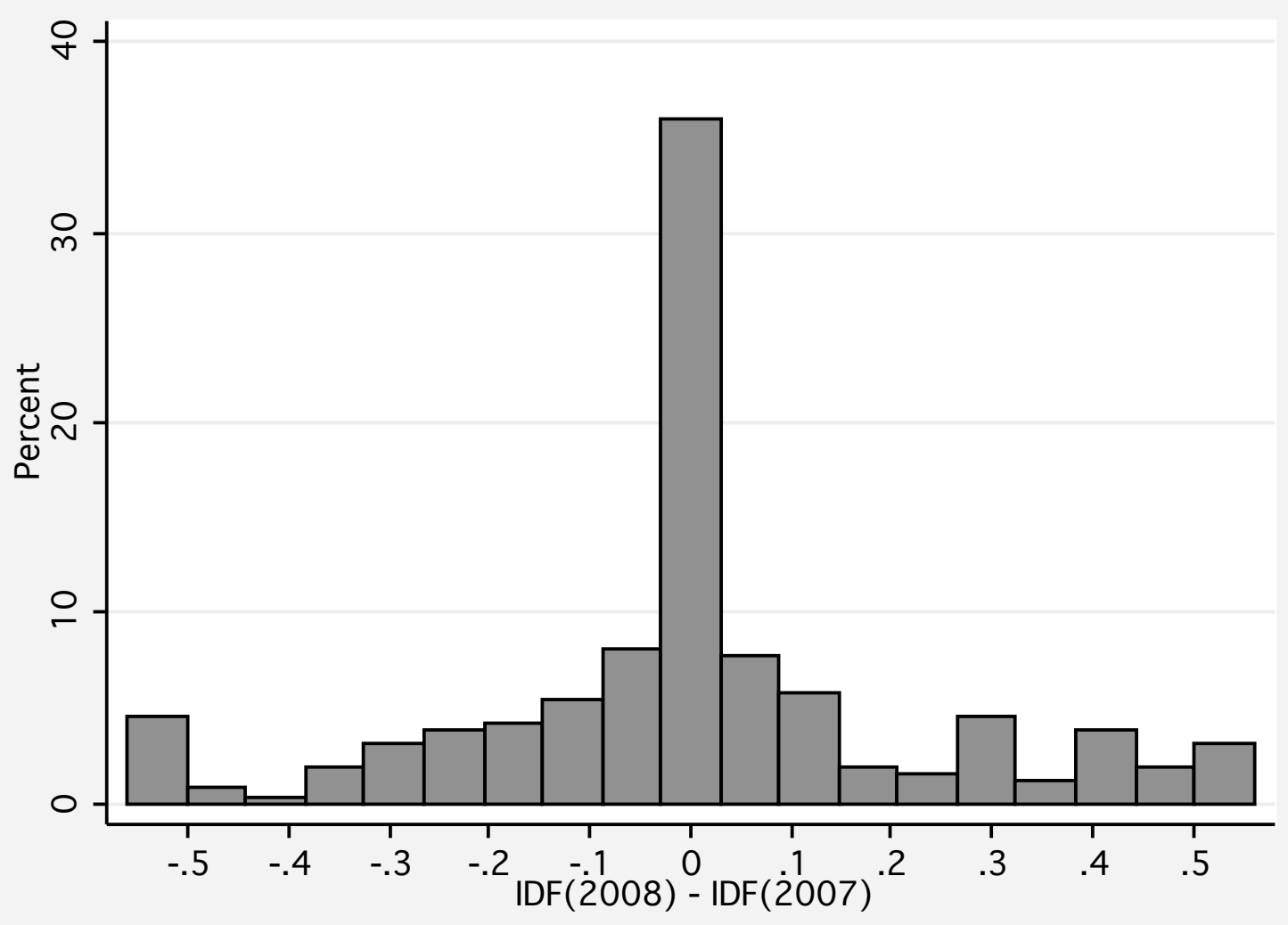

Note: The figure presents a histogram of the change in IDF: $\Delta$ IDF $=I D F_{2008}-I D F_{2007}$ for the returnee sample of 250 individuals. $\Delta$ IDF has mean 0.005 and standard error 0.015. 
A Appendix

A.1 Appendix Tables and Figures 


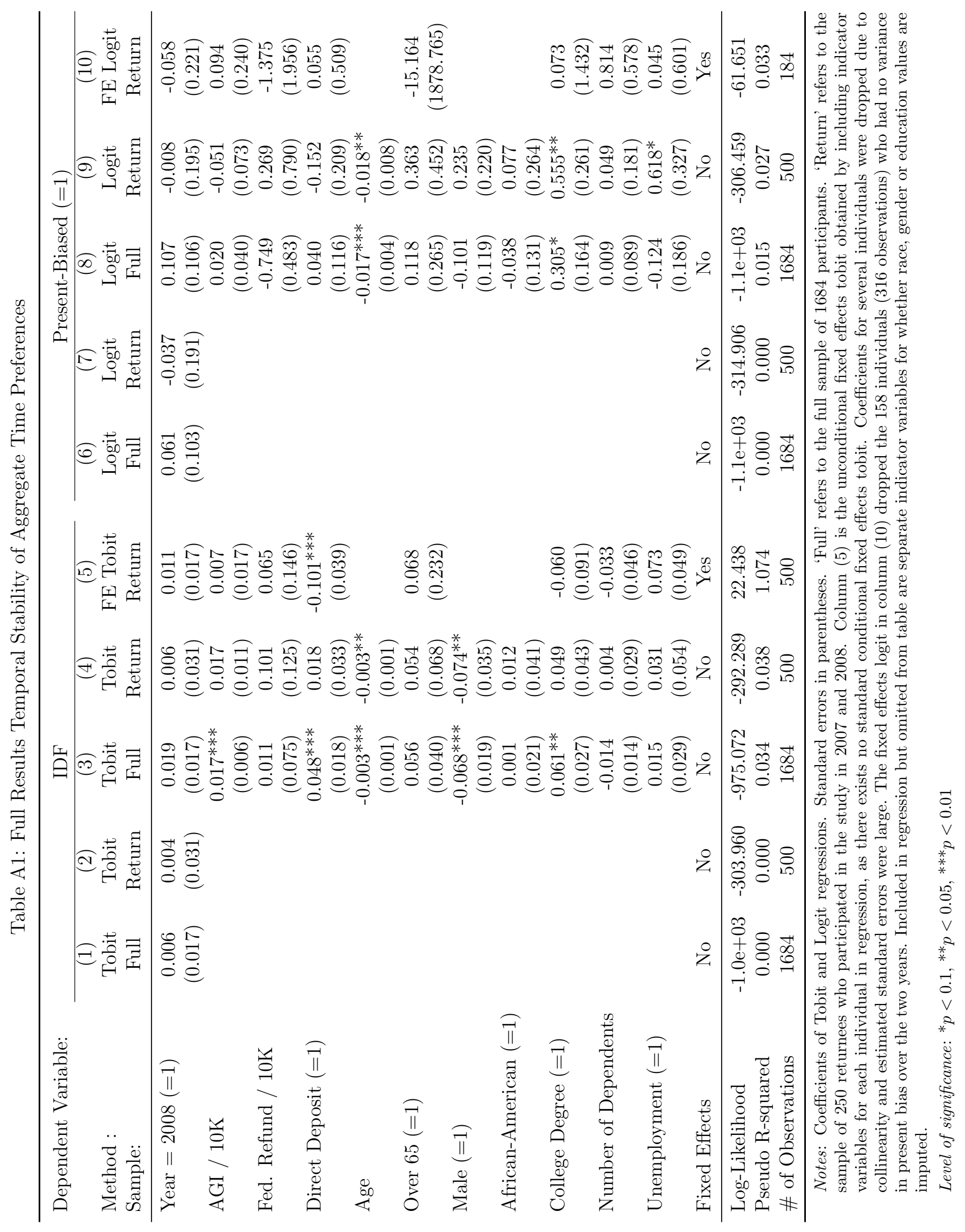


Table A2: Attrition Probit

\begin{tabular}{|c|c|}
\hline \multirow[t]{3}{*}{ Dependent Variable: } & Returnee $(=1)$ \\
\hline & $(1)$ \\
\hline & Probit \\
\hline \multirow[t]{2}{*}{ Distance: More than 2 miles } & $-0.197^{*}$ \\
\hline & $(0.102)$ \\
\hline \multirow{2}{*}{$\mathrm{PO} \operatorname{Box}(=1)$} & -0.407 \\
\hline & $(0.356)$ \\
\hline \multirow[t]{2}{*}{$\mathrm{IDF}_{2007}$} & 0.372 \\
\hline & $(0.230)$ \\
\hline \multirow[t]{2}{*}{ Present Biased 2007} & 0.034 \\
\hline & $(0.102)$ \\
\hline \multirow{2}{*}{ Adjusted Gross Income / 10K } & $0.106^{* * *}$ \\
\hline & $(0.036)$ \\
\hline \multirow[t]{2}{*}{ Federal Refund / 10K } & $0.872^{*}$ \\
\hline & $(0.458)$ \\
\hline \multirow{2}{*}{ Direct Deposit $(=1)$} & 0.110 \\
\hline & $(0.099)$ \\
\hline \multirow[t]{2}{*}{ Age } & $0.010^{* * *}$ \\
\hline & $(0.004)$ \\
\hline \multirow[t]{2}{*}{ Over $65(=1)$} & $0.476^{*}$ \\
\hline & $(0.249)$ \\
\hline \multirow[t]{2}{*}{ Male $(=1)$} & 0.067 \\
\hline & $(0.105)$ \\
\hline \multirow[t]{2}{*}{ African-American $(=1)$} & $0.239 * *$ \\
\hline & $(0.116)$ \\
\hline \multirow[t]{2}{*}{ College Degree $(=1)$} & 0.129 \\
\hline & $(0.141)$ \\
\hline \multirow[t]{2}{*}{ \# of Dependents } & $-0.201^{* *}$ \\
\hline & $(0.088)$ \\
\hline \multirow[t]{2}{*}{ Unemployment $(=1)$} & 0.009 \\
\hline & $(0.157)$ \\
\hline \multirow[t]{2}{*}{ Constant } & $-1.656^{* * *}$ \\
\hline & $(0.269)$ \\
\hline Log-Likelihood & -488.282 \\
\hline Pseudo R-Squared & 0.076 \\
\hline \# of Observations & 890 \\
\hline
\end{tabular}

Notes: Coefficient of probit regression. Standard errors in parentheses. Included in regression but omitted from table are separate indicator variables for whether race, gender or education values are imputed.

Level of significance: ${ }^{*} p<0.1,{ }^{* *} p<0.05,{ }^{* * *} p<$ 0.01 


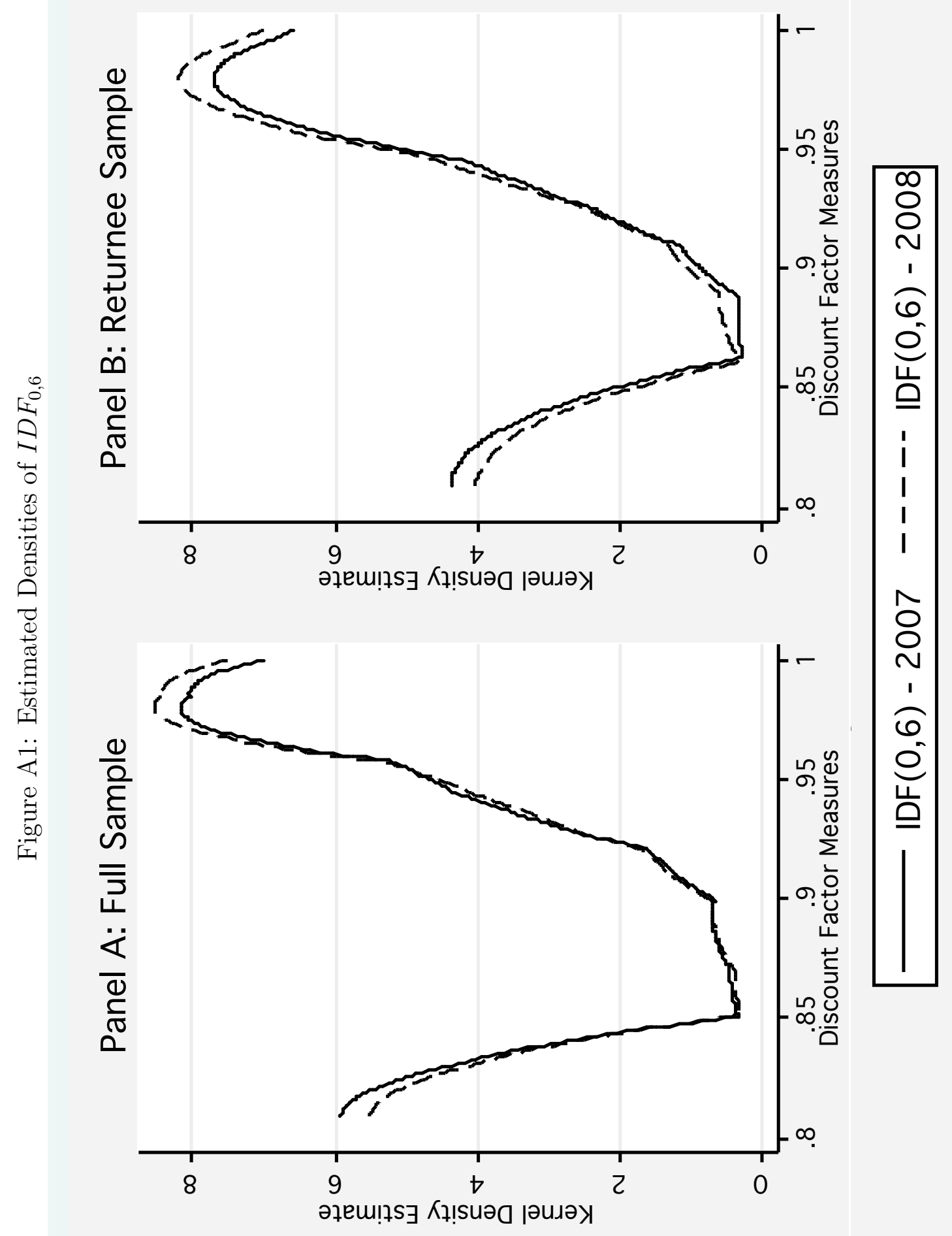

$\stackrel{\dot{F}}{\stackrel{0}{2}} \dot{\infty}$

대

乙昌

央苞

Z 00

:

들

$\infty$ ०

艺売

응

त)

훌.

웡

茪

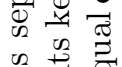

जै 考 잉

享远这

武

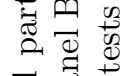

ซี ซี

山ै $\infty$

융

द्वा के

ॠ 20

昰官总

\&

\$ 1 .

๑ี

苞官

총

प艹

कै

。

.

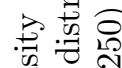

चี न

렬

웜ㅇㅇㅇ

⿶)

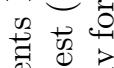

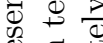

常

$<$ 设

०

สี

ค

نे

之े 


\section{A.2 Instructions}

As a tax filer at this Volunteer Income Tax Assistance site you are automatically entered in a raffle in which you could win up to $\$ 50$. Just follow the directions below:

How It Works: In the boxes below you are asked to choose between smaller payments closer to today and larger payments further in the future. For each row, choose one payment: either the smaller, sooner payment or the later, larger payment. When you return this completed form, you will receive a raffle ticket. If you are a winner, the raffle ticket will have a number on it from 1 to 22 . These numbers correspond to the numbered choices below. You will be paid your chosen payment. The choices you make could mean a difference in payment of more than $\$ 35$, so CHOOSE CAREFULLY!!!

RED BLOCK (Numbers 1 through 7): Decide between payment today and payment in one month BLACK BLOCK (Numbers 8 through 15): Decide between payment today and payment in six months BLUE BLOCK (Numbers 16 through 22): Decide between payment in six months and payment in seven months

Rules and Eligibility: For each possible number below, state whether you would like the earlier, smaller payment or the later, larger payment. Only completed raffle forms are eligible for the raffle. All prizes will be sent to you by normal mail and will be paid by money order. One out of ten raffle tickets will be a winner. You can obtain your raffle ticket as soon as your tax filing is complete. You may not participate in the raffle if you are associated with the EITC campaign (volunteer, business associate, etc.) or an employee (or relative of an employee) of the Federal Reserve Bank of Boston or the Federal Reserve System.

[Red Block; $t=0, \tau=1]$

TODAY VS. ONE MONTH FROM TODAY WHAT WILL YOU DO IF YOU GET A NUMBER BETWEEN 1 AND 7? Decide for each possible number if you would like the smaller payment for sure today or the larger payment for sure in one month? Please answer for each possible number (1) through (7) by filling in one box for each possible number.

Example: If you prefer $\$ 49$ today in Question 1 mark as follows: $\checkmark \$ 49$ today or $\$ 50$ in one month

If you prefer $\$ 50$ in one month in Question 1, mark as follows: $\$ 49$ today or $\checkmark \$ 50$ in one month

If you get number (1): Would you like to receive $\$ 49$ today or $\$ 50$ in one month

If you get number (2): Would you like to receive $\$ 47$ today or $\$ 50$ in one month

If you get number (3): Would you like to receive $\$ 44$ today or $\$ 50$ in one month

If you get number (4): Would you like to receive $\$ 40$ today or $\$ 50$ in one month

If you get number (5): Would you like to receive $\$ 35$ today or $\$ 50$ in one month

If you get number (6): Would you like to receive $\$ 29$ today or $\$ 50$ in one month

If you get number (7): Would you like to receive $\$ 22$ today or $\$ 50$ in one month

[Black Block; $t=0, \tau=6]$

TODAY VS. SIX MONTHS FROM TODAY WHAT WILL YOU DO IF YOU GET A NUMBER BETWEEN 8 AND 15? Now, decide for each possible number if you would like the smaller payment for sure today or the larger payment for sure in six months? Please answer each possible number (8) through (15) by filling in one box for each possible number.

If you get number (8): Would you like to receive $\$ 49$ today or $\$ 50$ in six months If you get number (9): Would you like to receive $\$ 47$ today or $\$ 50$ in six months If you get number (10): Would you like to receive $\$ 44$ today or $\$ 50$ in six months If you get number (11): Would you like to receive $\$ 40$ today or $\$ 50$ in six months If you get number (12): Would you like to receive $\$ 35$ today or $\$ 50$ in six months If you get number (13): Would you like to receive $\$ 29$ today or $\$ 50$ in six months If you get number (14): Would you like to receive $\$ 22$ today or $\$ 50$ in six months If you get number (15): Would you like to receive $\$ 14$ today or $\$ 50$ in six months

[Blue Block; $t=6, \tau=1$ ]

SIX MONTHS FROM TODAY VS. SEVEN MONTHS FROM TODAY WHAT WILL YOU DO IF YOU GET A NUMBER BETWEEN 16 AND 22? Decide for each possible number if you would like the smaller payment for sure in six months or the larger payment for sure in seven months? Please answer for each 
possible number (16) through (22) by filling in one box for each possible number.

If you get number (16): Would you like to receive $\$ 49$ in six months or $\$ 50$ in seven months If you get number (17): Would you like to receive $\$ 47$ in six months or $\$ 50$ in seven months If you get number (18): Would you like to receive $\$ 44$ in six months or $\$ 50$ in seven months If you get number (19): Would you like to receive $\$ 40$ in six months or $\$ 50$ in seven months If you get number (20): Would you like to receive $\$ 35$ in six months or $\$ 50$ in seven months If you get number (21): Would you like to receive $\$ 29$ in six months or $\$ 50$ in seven months If you get number (22): Would you like to receive $\$ 22$ in six months or $\$ 50$ in seven months 